\title{
Reduksiepotensiaal van $\beta$-diketone: Die effek van elektronskenkende, aromatiese en estersubstituentgroepe
}

\section{Authors:}

Jeanet Conradie, ${ }^{\mathrm{a}, \mathrm{b}}$

Nandisiwe GS Mateyise,

Marrigje M Conradie

Affiliasies:

a Departement Chemie, Universiteit van Troms $\varnothing$, N-9037 Troms $\varnothing$, Noorweë ${ }^{\mathrm{b}}$ Departement Chemie, Posbus 339, Universiteit van die Vrystaat, Bloemfontein, 9300, Suid-Afrika

Korresponderende outeur: Jeanet Conradie

E-pos: ConradJ@ufs.ac.za

Datums:

Ontvang: $\quad 29 / 07 / 19$

Aanvaar: $\quad 04 / 09 / 19$

Gepubliseer: 01/11/19

Hoe om hierdie artikel aan te haal:

Jeanet Conradie, Nandisiwe GS Mateyise, Marrigje M

Conradie, Reduksiepotensiaal van $\beta$-diketone: Die effek van

elektronskenkende,

aromatiese en ester-

substituentgroepe,

Suid-Afrikaanse Tydskrif vir

Natuurwetenskap en

Tegnologie 38(1) (2019).

https://doi.org/10.36303/

SATNT.2019.38.1.727

An English copy of this paper is available online at http://www.satnt.ac.za/ index.php/satnt/article/ view/727

Kopiereg:

(C) 2019. Authors.

Licensee: Die SuidAfrikaanse Akademie vir Wetenskap en Kuns. Hierdie werk is onder die Creative Commons Attribution License gelisensieer. 'n Elektrochemiese en berekeningschemiese studie van geselekteerde $\beta$-diketone word aangebied. Die effek van elektronskenkende, aromatiese en estergroepe op die 1 en 3 posisie van die $\beta$-diketone op die reduksiepotensiaal van $\beta$-diketone word geillustreer en bespreek. 'n Analise van die digtheidfunksionaalteorie-berekende (DFT-berekende) spin digtheidsprofiel en molekulêre elektrostatiese potensiaal van die gereduseerde $\beta$-diketone gee insig in die elektronverspreiding in die gereduseerde molekule. Daar is bevind dat die digtheidfunksionaalteorie-berekende (DFT-berekende) laagste ongevulde molekulêre orbitaal energieë $\left(E_{\text {LOMO }}\right)$ van die $\beta$-diketoon lineêr verband hou met die eksperimentele reduksiepotensiaal. Hierdie resultaat kan gebruik word om die verwagte eksperimentele reduksiepotensiaal van nuut-ontwerpte $\beta$-diketone te bepaal.

Sleutelwoorde: beta-diketoon; reduksiepotensiaal; eksperimentele-DFT verwantskappe, oligotiofeen

Reduction potential of $\beta$-diketones: Effect of electron donating, aromatic and ester substituent groups: An electrochemical and computational chemistry study of selected $\beta$-diketones is presented. The effect of electron donating, aromatic and ester groups on the 1 and 3 position of the $\beta$-diketones, on the reduction potential of $\beta$-diketones, is illustrated and discussed. An analysis of the density functional theory (DFT) calculated spin density profile and molecular electrostatic potential of the reduced $\beta$-diketone, gives insight into the electron distribution in the reduced molecule. DFT calculated lowest unoccupied molecular orbital energies $\left(E_{\text {LUMO }}\right)$ of the $\beta$-diketone relate linearly to the experimental reduction potential. This result could be used to determine the expected experimental reduction potential of newly designed $\beta$-diketones.

Keywords: beta-diketone; reduction potential; experimental-DFT relationships, oligothiophene

\section{Inleiding}

'n $\beta$-Diketoon (1,3-gesubstitueerde-propaan-1,3-dioon), $\mathrm{R}^{1} \mathrm{COCHC}(\mathrm{OH}) \mathrm{R}^{2}$, dien tipies as bidentate ligand met twee suurstofskenkersatome. Dit is 'n toutomeriese molekule wat bestaan as ' $n$ mengsel van enol- en ketoonvorms in ewewig met mekaar, met die enol as die oorwegende hoof vorm in oplossing (Conradie et al. 2008). $\beta$-Diketone is belangrike organiese reagense (Katritzky et al. 2004) en uitstekende chelate vir oorgangsmetale (Stary 1964), seldsame aardmetale (Gschneidner Jr et al. 2005) en aktinoïed-ione (Vigato et al. 2009). Vir al hierdie toepassings is 'n kennis van die stabiliteit van die $\beta$-diketone teenoor deprotonasie en reduksie belangrik. Die eksperimentele reduksiepotensiaal van 'n reeks van tien $\beta$-diketone, $\mathrm{R}^{1} \mathrm{COCHC}(\mathrm{OH}) \mathrm{R}^{2}, \mathbf{1}-\mathbf{9}$ en 11, soos aangetoon in Figuur 1, met verskillende substituentgroepe $R^{1}$ en $R^{2}$ op die $\beta$-diketoon, is reeds gerapporteer (Kuhn et al., 2011). Die gerapporteerde reduksiepotensiale wissel oor 'n gebied van $1.1 \mathrm{~V}$ tussen -1.05 en $-2.14 \mathrm{~V}$ vs $\mathrm{FcH} / \mathrm{FcH}^{+}$(waar $\mathrm{FcH}=$ ferroseen). Hierdie artikel het ten doel om (i) die gerapporteerde omvang van reduksiepotensiale van hierdie $\beta$-diketone te verhoog (Figuur 1), (ii) om verwantskappe tussen die eksperimentele reduksiepotensiale en DFT-berekende energieë te verskaf van hierdie $\beta$-diketone, en (iii) die invloed van elektronskenkende, elektrononttrekkende, aromatiese en estergroepe op die reduksiepotensiaal van 'n reeks $\beta$-diketone te illustreer. 


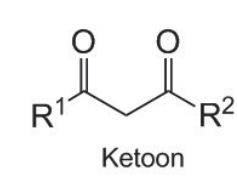<smiles>[R]C(=O)/C=C(/[R])O</smiles>
Enol-R ${ }^{1}$

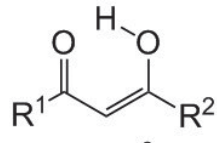
Enol-R ${ }^{2}$

\begin{tabular}{|llllllll|}
\hline & $\mathbf{R}^{1}$ & $\mathbf{R}^{2}$ & & $\mathbf{R}^{1}$ & $\mathbf{R}^{2}$ & \multicolumn{1}{c|}{$\mathbf{R}^{1}$} & $\mathbf{R}^{\mathbf{2}}$ \\
1. & $\mathrm{CF}_{3}$ & $p-\mathrm{C}_{6} \mathrm{H}_{4}-\mathrm{NO}_{2}$ & 6. & $\mathrm{CF}_{3}$ & $\mathrm{C}\left(\mathrm{CH}_{3}\right)_{3}$ & 11. $\mathrm{Ph}$ & $\mathrm{CH}_{3}$ \\
2. & $\mathrm{CF}_{3}$ & $\mathrm{CF}_{3}$ & 7. & $\mathrm{Th}$ & $\mathrm{Th}$ & 12. $\left.\mathrm{C}_{(} \mathrm{CH}_{3}\right)_{3}$ & $\mathrm{C}\left(\mathrm{CH}_{3}\right)_{3}$ \\
3. & $\mathrm{CF}_{3}$ & $\mathrm{Th}$ & 8. & $\mathrm{Ph}$ & $\mathrm{Th}$ & 13. $\mathrm{CH}_{3}$ & $\mathrm{OCH}_{3}$ \\
4. & $\mathrm{CF}_{3}$ & $\mathrm{Ph}$ & 9. & $\mathrm{Ph}$ & $\mathrm{Ph}$ & 14. $\mathrm{CF}_{3}$ & $\mathrm{C}_{4} \mathrm{H}_{2} \mathrm{~S}-\mathrm{Th}$ \\
5. & $\mathrm{CF}_{3}$ & $\mathrm{CH}$ & 10. & $\mathrm{CH}$ & $\mathrm{CH}_{3}$ & 15. $\mathrm{CF}_{3}$ & $\mathrm{Fu}$ \\
\hline
\end{tabular}

FIGUUR 1: Die isomeriese vorms en nommering van die $\beta$-diketone wat in hierdie studie gebruik word. $\mathrm{Th}=\mathrm{C}_{4} \mathrm{H}_{3} \mathrm{~S}, \mathrm{Ph}=\mathrm{C}_{6} \mathrm{H}_{5}, \mathrm{Fu}=\mathrm{C}_{4} \mathrm{H}_{3} \mathrm{O}$.

\section{Materiaal en metodes}

\section{Sintese}

Die oligotiofeen $\beta$-diketone 7 en 8 is gesintetiseer en gekarakteriseer soos beskryf in die literatuur (Conradie et al. 2008), terwyl $\beta$-diketoon 14 uit 5-asetiel-2,2'-bitiofeen gesintetiseer is soos beskryf in Skema 1. Die ander $\beta$-diketone (Sigma-Aldrich) is gebruik soos ontvang, sonder verdere suiwering.

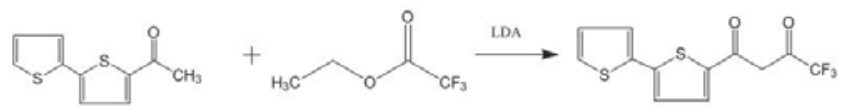

SKEMA 1: Sintese van 1-[2,2'-bitiofeen]-5-iel-4,4,4-trifluoor-1,3-butaandioon, 14, vanaf 5-asetiel-2,2'-bitiofeen en etieltrifluoorasetaat.

\section{5-Asetiel-2,2'-bitiofeen}

2,2'-Bitiofeen (1.024 g, $6 \mathrm{mmol})$ is gemeng met asynsuuranhidried (1.234 g, $12 \mathrm{mmol})$ en sinkchloried (0.0245 g, $0.18 \mathrm{mmol})$. Die donkergroen oplossing is vir 'n periode van vier ure teen 'n temperatuur van $100{ }^{\circ} \mathrm{C}$ verhit. $\mathrm{Na}$ afkoeling, is water $(40 \mathrm{~mL})$ by die soliede bruin stof gevoeg. Diëtieleter is bygevoeg en die presipitaat is fyngemaal. Die fyngemaalde presipitaat is sorgvuldig gewas met diëtieleter. Die oorblywende neerslag is die byproduk, voorlopig toegeken as $\left(\mathrm{CH}_{3} \mathrm{CO}\right)_{2}\left(\mathrm{C}_{4} \mathrm{H}_{3} \mathrm{~S}\right)_{2^{\prime}}$ volgens die ${ }^{1} \mathrm{H}$ KMR spektrum. Die filtraat wat die verlangde produk bevat, is geneutraliseer met 'n natriumkarbonaatoplossing $(0.05 \mathrm{M})$. Die organiese laag is met water $(3 \times 50 \mathrm{~mL})$ gewas en met magnesiumsulfaat gedroog. Die magnesiumsulfaat is afgefiltreer en die oplosmiddel is onder verminderde druk verwyder, wat 'n oranje presipitaat tot gevolg gehad het. Die oranje presipitaat is met metanol gewas om die ongereageerde uitgangstowwe te verwyder. Die oplosmiddel is onder verminderde druk verwyder. Spektroskopies suiwer 5-asetiel-2,2'-bitiofeen (oranje poeier) is verkry (0.538 g, $41.7 \%$ opbrengs). $\delta_{\mathrm{H}}\left(300 \mathrm{MHz}, \mathrm{CDCl}_{3}\right): 2.551\left(3 \mathrm{H}, \mathrm{s}, \mathrm{CH}_{3}\right)$, $7.061\left(1 \mathrm{H}, \mathrm{dd},{ }^{3} \mathrm{~J}=4 \mathrm{~Hz},{ }^{3} \mathrm{~J}=5 \mathrm{~Hz}, \mathrm{CH}\right), 7.174\left(1 \mathrm{H}, \mathrm{d},{ }^{3} \mathrm{~J}=4\right.$ $\mathrm{Hz}, \mathrm{CH}), 7.336-7.314$ ( 2H, m, CH), $7.589\left(1 \mathrm{H}, \mathrm{d},{ }^{3} \mathrm{~J}=4 \mathrm{~Hz}\right.$, $\mathrm{CH})$.

\section{1-[2,2'-Bitiofeen]-5-iel-4,4,4-trifluoor-1,3-butaandioon, 14}

$\beta$-diketoon 14 is gesintetiseer onder streng Schlenk toestande. Die sisteem is met' $n$ vlam gedroog en ontgas onder argongas. 'n Argonatmosfeer is regdeur die reaksie gehandhaaf. 5-Asetiel-2,2'-bitiofeen $(2.000 \mathrm{~g}, 9.6 \mathrm{mmol})$ is in THF $(15 \mathrm{~mL})$ opgelos en vir 'n paar minute geroer. Litium diïsopropielamied, LDA (5 mL 2.0 M oplossing in THF / heptaan / etielbenseen, $10 \mathrm{mmol}$ ) is stadig by die oplossing gevoeg, op 'n ysbad gehou en toegelaat om vir 15 minute by $0{ }^{\circ} \mathrm{C}$ te roer. Etieltrifluoorasetaat $(1.2 \mathrm{~mL}, 10.0 \mathrm{mmol})$ is by die oranje oplossing gevoeg. Die reaksiemengsel is vir 24 uur by kamertemperatuur geroer. Die donkerbruin oplossing is met $\mathrm{HCl}(100 \mathrm{~mL}, 0.3 \mathrm{M})$ aangesuur en met diëtieleter $(2 \times 50 \mathrm{~mL})$ geëkstraheer. Die organiese laag is deeglik met water $(2 \mathrm{x}$ $100 \mathrm{~mL}$ ) gewas en met magnesiumsulfaat gedroog. Die oplosmiddel is onder verminderde druk verwyder. Spektroskopies-suiwer 1-[2,2'-bitiofeen]-5-iel-4,4,4-trifluoor-1,3-butaandioon is verkry $(2.559 \mathrm{~g}, 87.6 \%) . \delta_{\mathrm{H}}\left(300 \mathrm{MHz}, \mathrm{CDCl}_{3}\right)$ : $6.415(1 \mathrm{H}, \mathrm{s}, \mathrm{CH}), 7.090\left(1 \mathrm{H}, \mathrm{dd},{ }^{3} \mathrm{~J}=4 \mathrm{~Hz},{ }^{3} \mathrm{~J}=5 \mathrm{~Hz}, \mathrm{CH}\right)$, $7.242\left(1 \mathrm{H}, \mathrm{d},{ }^{3} \mathrm{~J}=4 \mathrm{~Hz}, \mathrm{CH}\right), 7.366-7.391(2 \mathrm{H}, \mathrm{m}, \mathrm{CH}), 7.737$ $\left(1 \mathrm{H}, \mathrm{d},{ }^{3} \mathrm{~J}=4 \mathrm{~Hz}, \mathrm{CH}\right)$.

\section{Teoretiese Berekeninge}

DFT berekeninge is uitgevoer met behulp van (i) die B3LYP funksionaal met die tripel- $\zeta$ basisstel $6-311 G(d, p)$, soos geïmplementeer in die Gaussian 16 pakket (Frisch et al. 2016), en (ii) die OLYP funksionaal met die alle elektron

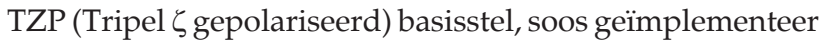
in die Amsterdam Digtheidsfunksionaal program (ADF2018) (Te Velde et al. 2001). Frekwensie analise is gedoen op alle verbindings om te bevestig dat die geoptimiseerde strukture nie enige imaginêre frekwensies vertoon nie, dus dat dit werklike minimum energie strukture is. Berekeninge is in die gasfase gedoen, sowel as die eksperimentele oplosmiddel van die elektrochemiese studie, $\mathrm{CH}_{3} \mathrm{CN}$. Vir die oplosmiddelberekeninge wat Gaussian 16 gebruik, is die solvasiemodeldigtheid (SMD) (Marenich et al. 2009) polariseerbare kontinuummodel (PCM) gebruik, met 'n integrale vergelyking formalisme variant (IEF-PCM) (Skeyner et al., 2015). Vir die oplosmiddelberekeninge wat die ADF gebruik, is die COSMO (geleiersoortkeuringsmodel) van solvasie (Klamt en Schüürmann 1993, Klamt 1995, Klamt en Jones 1996) gebruik.

Om die eksperimentele en berekende data van verbindings $1,3-6,11,13-15$ te vergelyk, is 'n effektiewe berekende energie bepaal deur gebruik te maak van die verhouding van die relatiewe populasie van die twee enolisomere, soos bepaal deur die Boltzmann-vergelyking.

Om die reaktiewe gebiede vir elektrofiele en nukleofiele aanvalle vir die verbindings te voorspel, is 'n molekulêre elektrostatiese potensiaal, MESP-oppervlak gesimuleer vanaf die geoptimaliseerde B3LYP-geometrie, met behulp van die sleutelwoord chelp (ladings van elektrostatiese 
potensiaal) in Gaussian 16. Die MESP, $\mathrm{V}(r)$ op 'n punt $r$, is bereken deur die standaardvergelyking te gebruik,

$$
V(r)=\sum_{A}^{N} \frac{Z_{A}}{\left|r-R_{A}\right|}-\frac{\rho\left(r^{\prime}\right) d^{3} r^{\prime}}{\left|r-r^{\prime}\right|}
$$

waar die sommering oor al die kerne $A$ in die verbinding loop. $Z_{A}$ is die lading op die kern $A$ op posisie $R_{A^{\prime}} \rho\left(r^{\prime}\right)$ is die elektrondigtheid en $N$ is die totale aantal kerne (Gadre en Shirsat 2000).

\section{Elektrochemie}

Elektrochemiese studies deur middel van sikliese voltammetrie (SV) is op $0.002 \mathrm{M}$ of op versadigde verbinding oplossings van die komplekse in droë asetonitriel uitgevoer, wat $0.1 \mathrm{M}$ tetra- $n$-butielammoniumheksafluoorfosfaat $\left(\left[{ }^{\mathrm{n}} \mathrm{Bu}_{4} \mathrm{~N}\right]\left[\mathrm{PF}_{6}\right]\right)$ bevat as ondersteunende elektroliet, onder 'n kombers van gesuiwerde argon, by $25^{\circ} \mathrm{C}$, met behulp van 'n BAS 100B/W elektrochemiese ontleder. 'n Drieelektrodesel is gebruik, met 'n glas-koolstof (oppervlakte $\left.7.07 \times 10^{-6} \mathrm{~m}^{2}\right)$ werkelektrode, Pt-hulpelektrode en 'n Ag/ $\mathrm{Ag}^{+}\left(0.010 \mathrm{M} \mathrm{AgNO}\right.$ in $\left.\mathrm{CH}_{3} \mathrm{CN}\right)$ verwysingselektrode (Sawyer en Roberts 1974), gemonteer op 'n Luggin kapillêr (Evans et al. 1983). Skanderingstempo's vir die SVe is 0.05 $-5.00 \mathrm{~V} \mathrm{~s}^{-1}$. Opeenvolgende eksperimente onder dieselfde eksperimentele toestande het getoon dat alle oksidasie- en reduksiepotensiale binne $0.010 \mathrm{~V}$ herhaalbaar was. Al die genoemde potensiale is met verwysing na $\mathrm{FcH} / \mathrm{FcH}^{+}$koppeling, soos voorgestel deur IUPAC (Gritzner en Kuta 1984). Ferroseen $(\mathrm{FcH})$ het 'n piekskeiding van $\Delta E_{\mathrm{p}}=E_{\mathrm{pa}}$ $E_{\mathrm{pk}}=0.070 \mathrm{~V}$ en piekstroomverwantskap $i_{p k} / i_{p a}=1.00$ onder ons eksperimentele toestande vertoon ( $\mathrm{pa}=$ piek anodies en $\mathrm{pk}=$ piek katodies).

\section{Resultate en bespreking Elektrochemie}

Die sikliese voltammogramme (SVe) van $\beta$-diketone $\left(\mathrm{CH}_{3} \mathrm{COCHC}(\mathrm{OH}) \mathrm{CH}_{3}\right) \mathbf{1 0},\left(\mathrm{C}\left(\mathrm{CH}_{3}\right)_{3} \mathrm{COCHC}(\mathrm{OH}) \mathrm{C}\left(\mathrm{CH}_{3}\right)_{3}\right)$ 12 en $\left(\mathrm{CH}_{3} \mathrm{COCHC}(\mathrm{OH})\left(\mathrm{OCH}_{3}\right)\right) 13$ word in Figuur 2 vertoon. Die eksperimentele reduksiepotensiaal teen 'n skanderingstempo van $0.100 \mathrm{~V} \mathrm{~s}^{-1}$, soos verkry uit die SVe, word in Tabel 1 getabuleer, tesame metreeds gerapporteerde reduksiepotensiale van $\beta$-diketone, wat onder dieselfde eksperimentele toestande verkry is. Die resultate toon dat deur die elektronskenkersgroepe $\mathrm{CH}_{3}$ of $\mathrm{C}\left(\mathrm{CH}_{3}\right)_{3}$ op die $\beta$-diketone 10 en 12 in te sluit, die eksperimentele reduksiepotensiaal na meer negatiewe waardes verskuif het, naamlik -2.618 en $-2.748 \mathrm{~V}$ vs $\mathrm{FcH} / \mathrm{FcH}^{+}$onderskeidelik. Die estergroep $\mathrm{OCH}_{3}$ op die $\beta$-diketoon 13 het egter gelei tot 'n nog meer negatiewe eksperimentele reduksiepotensiaal van $-3.017 \mathrm{~V}$ vs $\mathrm{FcH} / \mathrm{FcH}^{+}$. Hierdie reduksie waardes is tot $0.9 \mathrm{~V}$ meer negatief as die mees negatiewe waarde van die gerapporteerde reduksie waardes van 'n reeks $\beta$-diketone (Kuhn et al. 2011) wat tussen -1.05 en -2.14 $\mathrm{V}$ vs $\mathrm{FcH} / \mathrm{FcH}^{+}$gewissel het. Die reduksiepotensiaal verkry vir $\left(\mathrm{CH}_{3} \mathrm{COCHC}(\mathrm{OH}) \mathrm{CH}_{3}\right) 10,-2.618 \mathrm{~V}$ vs $\mathrm{FcH} / \mathrm{FcH}^{+}$, stem ooreen met ' $\mathrm{n}$ gepubliseerde resultaat van $-2.20 \mathrm{~V}$ vs SCE (Neal en Murray 1970) wat $-2.62 \mathrm{~V}$ vs $\mathrm{FcH} / \mathrm{FcH}^{+}$(Pombeiro 2005) is.

Die SVe van die $\beta$-diketone $\mathbf{1 0}, \mathbf{1 2}$ en $\mathbf{1 3}$ is chemies en elektrochemies onomkeerbaar, soos verwag, as gevolg van die onstabiliteit van die radikale anioon wat tydens reduksie vorm (Buchta en Evans 1970, Buchta en Evans 1968). Daar is egter opgemerk dat SVe van $\beta$-diketone $\mathrm{R}^{1} \mathrm{COCHC}(\mathrm{OH}) \mathrm{R}^{2}$ waarvan beide die substituentgroepe $\mathrm{R}^{1}$

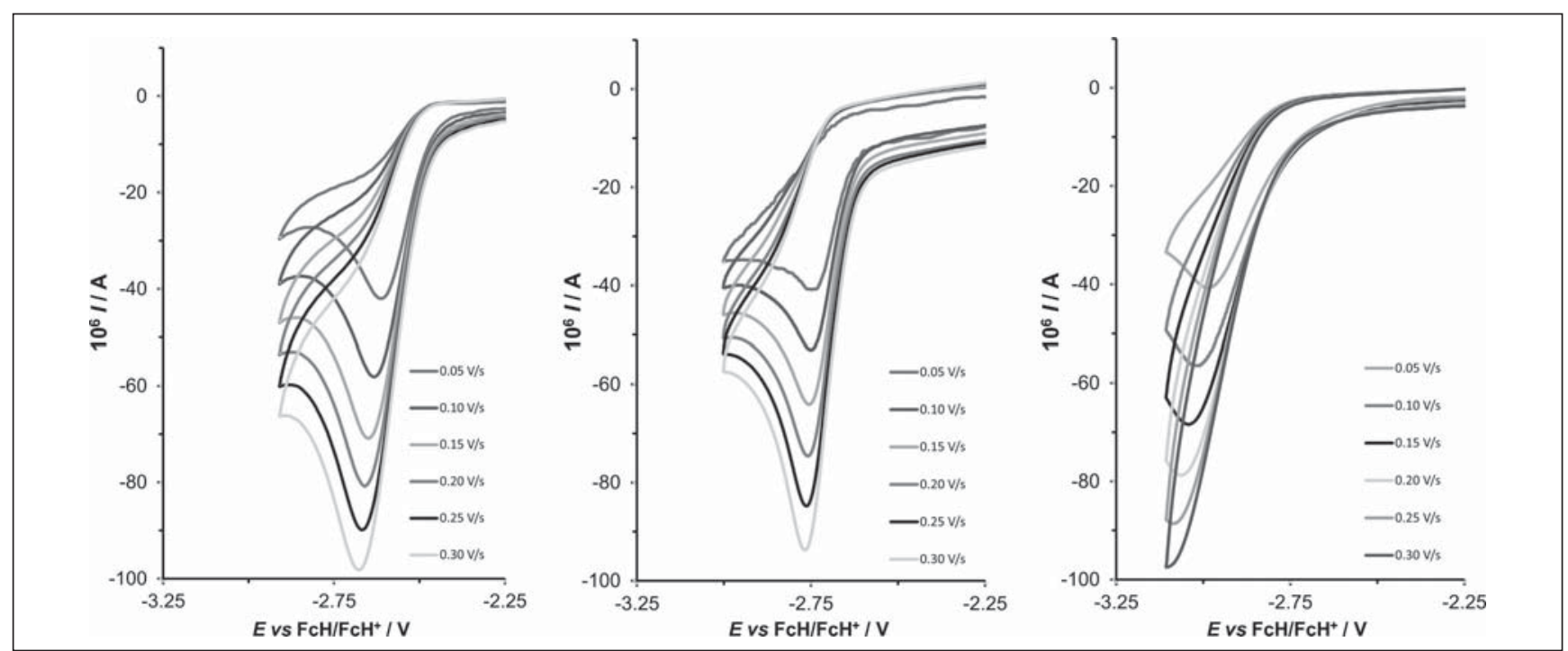

FIGUUR 2: Sikliese voltammogramme $\left(v s \mathrm{FcH} / \mathrm{FcH}^{+}\right)$teen die aangeduide skanderingstempo $\left(\mathrm{V} \mathrm{s}^{-1}\right)$ vir $\beta$-diketone $\left.\left(\mathrm{CH} \mathrm{COCHC}_{3} \mathrm{OH}\right) \mathrm{CH}{ }_{3}\right) 10($ links $),\left(\mathrm{C}(\mathrm{CH})_{3} \mathrm{COCHC}(\mathrm{OH})\right.$ $\left.\mathrm{C}\left(\mathrm{CH}_{3}\right)_{3}\right) 12$ (middel) en $\left(\mathrm{CH}_{3} \mathrm{COCHC}(\mathrm{OH})\left(\mathrm{OCH}_{3}\right)\right) \mathbf{1 3}$ (regs), by $25^{\circ} \mathrm{C}$. Oplosmiddel/elektroliet $=0.1 \mathrm{M}\left[{ }^{\mathrm{n}} \mathrm{Bu}_{4} \mathrm{~N}\right]\left[\mathrm{PF}_{6}\right] / \mathrm{CH}_{3} \mathrm{CN}$. 
en $\mathrm{R}^{2}$ aromaties is, ' $\mathrm{n}$ her-oksidasiepiek vertoon by slegs hoër skanderingstempo's. Twee aromatiese substituente in die 1- en 3-posisie onderskeidelik, stabiliseer die radikale anioon chemies wat tydens die reduksie vorm, op die tydskaal van SVe by hoë skanderingstempo's (> $\left.2 \mathrm{~V} \mathrm{~s}^{-1}\right)$ (Kuhn et al., 2011; Buchta en Evans 1968). In Figuur 3 word die SVe van $\beta$-diketone (ThCOCHC(OH)Th) 7 en (ThCOCHC(OH)Ph) 8, wat elk twee aromatiese substituente bevat, vergelyk met die $\mathrm{SV}$ van $\left(\mathrm{CF}_{3} \mathrm{COCHC}(\mathrm{OH})\left(\mathrm{C}_{4} \mathrm{H}_{2} \mathrm{~S}\right.\right.$ Th)) 14, wat twee verbinde aromatiese tiëniel groepe bevat in die een substituentposisie. Ons sien dat die twee aromatiese groepe in die een substituentposisie nie tot chemiese omkeerbare gedrag by hoër skanderingstempo's gelei het nie. Die reduksiepotensiaal van $\left(\mathrm{CF}_{3} \mathrm{COCHC}(\mathrm{OH})\right.$ $\left.\left(\mathrm{C}_{4} \mathrm{H}_{2} \mathrm{~S}-\mathrm{Th}\right)\right)$ 14, $\left(-1.470 \mathrm{~V}\right.$ vs $\left.\mathrm{FcH} / \mathrm{FcH}^{+}\right)$wat twee tiëniel groepe bevat, is effens meer positief as die reduksiepotensiaal van $\left(\mathrm{CF}_{3} \mathrm{COCHC}(\mathrm{OH}) \mathrm{Th}\right) 3(-1.541 \mathrm{~V}$ vs $\mathrm{FcH} /$ $\left.\mathrm{F}_{\mathrm{CH}}{ }^{+}\right)$, wat slegs een tiëniel groep bevat.

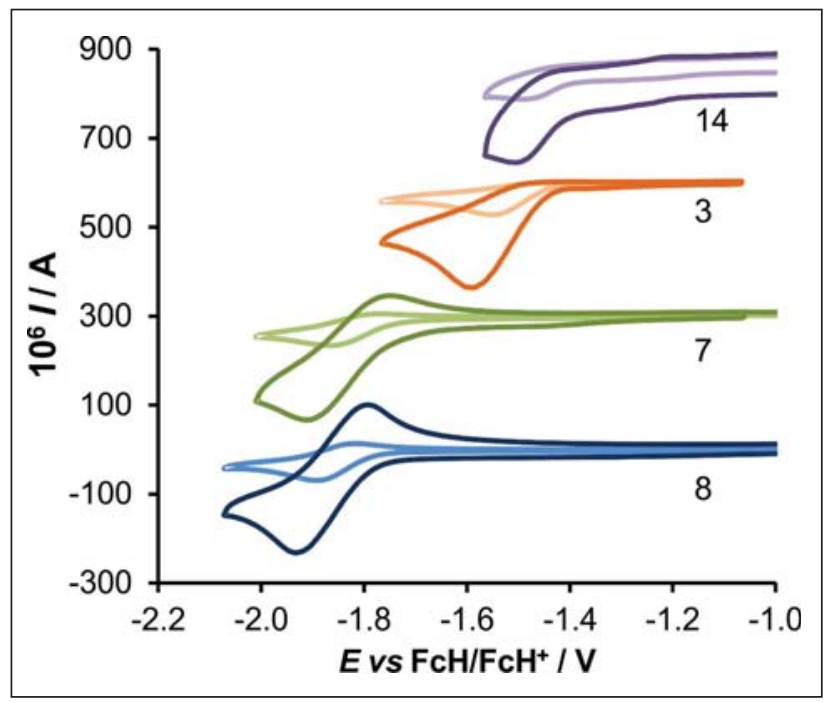

FIGUUR 3: Sikliese voltammogramme (vs $\left.\mathrm{FcH} / \mathrm{FcH}^{+}\right)$van oligotiofeen $\beta$-diketone $\quad\left(\mathrm{CF}_{3} \mathrm{COCHC}(\mathrm{OH})\left(\mathrm{C}_{4} \mathrm{H}_{2} \mathrm{~S}-\mathrm{Th}\right) \quad \mathbf{1 4}, \quad\left(\mathrm{CF}_{3} \mathrm{COCHC}(\mathrm{OH}) \mathrm{Th}\right) \quad 3\right.$ ( ThCOCHC(OH)Th) 7 en (ThCOCHC(OH) Ph) 8, teen skanderingstempo's 0.20 en $2.00 \mathrm{~V} \mathrm{~s}^{-1}$, by $25^{\circ} \mathrm{C}$. Oplosmiddel/elektroliet $=0.1 \mathrm{M}\left[{ }^{n} \mathrm{Bu}_{4} \mathrm{~N}\right]\left[\mathrm{PF}_{6}\right] / \mathrm{CH}_{3} \mathrm{CN}$.

\section{Effek van elektronskenkende en aromatiese groepe}

Die R-sygroepe $\left(\mathrm{R}^{1}\right.$ en $\left.\mathrm{R}^{2}\right)$ op die $\beta$-diketone, $\mathrm{R}^{1} \mathrm{COCHC}(\mathrm{OH})$ $R^{2}, 1$ - 15, het verskillende elektronskenkende (of elektrononttrekkende) eienskappe as gevolg van induktiewe $\left(\mathrm{CF}_{3}\right.$ en alifatiese groepe) of resonansie-effekte. Die resonansie-effek sluit elektronskenking in van aromatiese groepe (feniel, tiëniel of furiel) of van 'n alleenpaarelektrone (op $\mathrm{O}$ van estergroep $\mathrm{OCH}_{3}$ ). Empiriese parameters wat gebruik word om die elektronskenkende eienskappe van die R-groepe te kwantifiseer is Gordyskaal-groepelektronegatiwiteite, $\chi_{R^{\prime}}$ (Wells 1968, Kagarise $1955)$ en Hammett-meta-substituentkonstantes, $\sigma_{\text {meta, }}$ (McDaniel en Brown 1958, Hammett 1935, Hammett 1937,
Hansch et al. 1991). As gevolg van goeie kommunikasie (via induksie en resonansie) tussen die R-groepe en die $\beta$-diketonato-ruggraat, is die elektroniese effek van elke groep op die $\beta$-diketoon additief, dus word die somtotaal van die elektronegatiwiteite $\left(\chi_{\mathrm{R} 1}+\chi_{\mathrm{R} 2}\right)$ en Hammett meta substituentkonstantes $\left(\sigma_{\mathrm{R} 1}+\sigma_{\mathrm{R} 2}\right)$ gebruik. Die invloed van die verskillende $\mathrm{R}^{1}$ - en $\mathrm{R}^{2}$-groepe op die reduksiepotensiaal van $\beta$-diketone, $\mathrm{R}^{1} \mathrm{COCHC}(\mathrm{OH}) \mathrm{R}^{2}, \mathbf{1}-\mathbf{1 5}$, word in Figuur 4 geillustreer met die gegewens wat in Tabel 1 gegee word. Wanneer daar gefokus word op komplekse 2, 5, 6, 10 en 12, waarvan die alifatiese R-groepe 'n suiwer $\sigma$ induktiewe effek het, word lineêre verwantskappe verkry tussen die reduksiepotensiaal en die die somtotaal van elektronskenkende (of elektrononttrekkende) effek, wanneer dit uitgedruk word as $\left(\sigma_{\mathrm{R} 1}+\sigma_{\mathrm{R} 2}\right)$ of $\left(\chi_{\mathrm{R} 1}+\chi_{\mathrm{R} 2}\right)$ van die betrokke R-groepe, $\mathrm{R}=\mathrm{CH}_{3^{\prime}} \mathrm{C}\left(\mathrm{CH}_{3}\right)_{3}$ of $\mathrm{CF}_{3}$. Die reduksiepotensiaal van $\beta$-diketoon 12 (wat twee sterk elektronskenkende $\mathrm{C}\left(\mathrm{CH}_{3}\right)_{3}$-groepe bevat) is $1.5 \mathrm{~V}$ meer negatief as die reduksiepotensiaal van $\beta$-diketoon 2 (wat twee sterk elektrononttrekkende $\mathrm{CF}_{3}$-groepe bevat). Net so is die reduksiepotensiaal van $\beta$-diketoon 5 (wat slegs een sterk elektrononttrekkende $\mathrm{CF}_{3}$-groep bevat) $0.6 \mathrm{~V}$ meer negatief as dié van $\beta$-diketoon 2 . Die effek van' $n$ aromatiese R-groep op die reduksiepotensiaal van $\beta$-diketone is egter ' $n$ wisselwerking tussen die induktiewe effek deur die $\sigma$-sisteem en 'n resonansie-effek deur die $\pi$-sisteem (sien ook die laagste onbesette molekulêre orbitaal in Figuur 7 en die verbandhoudende bespreking in die volgende afdeling). Die resonansie-effek lei tot 'n minder negatiewe reduksiepotensiaal as wat verwag word (verbinding word makliker gereduseer) indien slegs die induktiewe effekte teenwoordig sou wees. Die datapunte van al die $\beta$-diketone $1,3,4,7,8,9,11,14$ en 15, (aangedui met rooi kruise) in Figuur 4, wat ten minste een aromatiese groep bevat, lê bo die passingslyn wat die suiwer induktiewe effek van die R-groepe op die reduksiepotensiaal aantoon. Dit impliseer dat die stabilisering van die elektrondigtheid van die neutrale $\beta$-diketoon deur resonansie lei tot 'n hoër elektronaffiniteit van die neutrale $\beta$-diketoon om 'n elektron op te neem (om gereduseer te word). Die afwyking van $\beta$-diketone wat ' $n$ aromatiese groep bevat vanaf die tendenslyn wat die suiwer induktiewe effek in Figuur 4 (links) toon, waar die (Gordy-skaal) groepelektronegatiwiteite in ag geneem word, is groter, omdat hierdie parameter slegs afhanklik is van induktiewe elektrononttrekkendeeffekte van diesubstituente. Elektronskenking via alleenpaarresonansie (op die $\mathrm{O}$ van die estergroep $\mathrm{OCH}_{3}$ in $\beta$-diketoon 13) lei egter tot 'n meer negatiewe reduksiepotensiaal, soos verwag word deur 'n suiwer induktiewe effek (blou driehoek in Figuur 4). Die effek van elektronskenking via alleenpaarresonansie is dus om die neutrale $\beta$-diketoon te stabiliseer, die elektrondigtheid op die ruggraat van die $\beta$-diketoon te verhoog, wat dit moeiliker maak om by 'n laer potensiaal te reduseer (laer elektronaffiniteit), sien Figuur 5. 


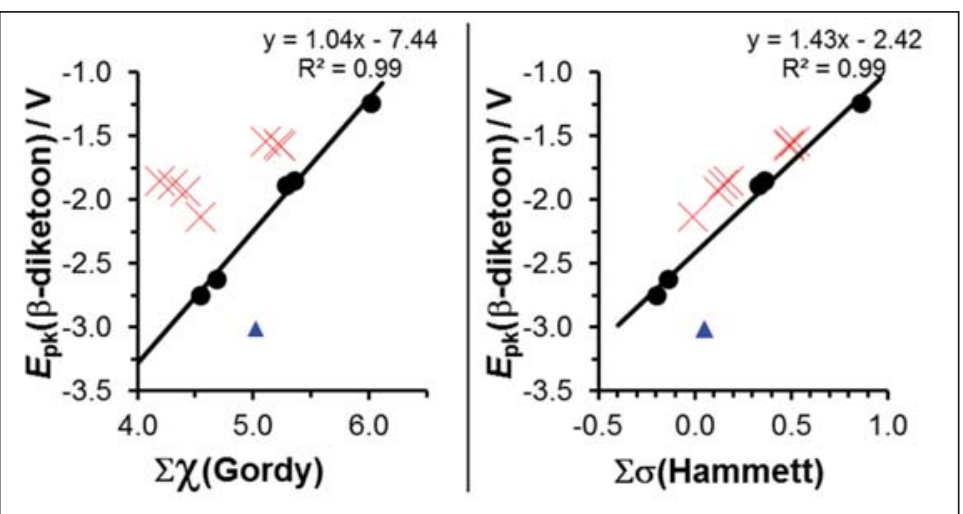

FIGUUR 4: Illustrasie van die invloed van R-groepe op die reduksiepotensiaal ( $E_{\text {in }}$ in $\mathrm{V} v \mathrm{vcH}$ / $\mathrm{FCH}^{+}$) van $\beta$-diketone 1 - 15 in terme van die som van die Gordy-skaalgroepelektronegatiwiteite $\left(\chi_{R 1}+\chi_{R 2}\right)$ (links) en die som van Hammett-meta-substituentkonstantes $\left(\sigma_{R 1}+\sigma_{R 2}\right)$ (regs). Datapunte van $\beta$-diketone met groepe wat 'n suiwer induktiewe effek het, word getoon met swart sirkels $(\cdot), \beta$-diketone met aromatiese groepe met rooi kruise $(x)$ en die $\beta$-diketone met 'n estergroep met ' $n$ blou driehoek (A). Die tendenslyn is gepas deur die swart sirkels (suiwer induktiewe effek, verbindings 2, 5, 6, 10 en 12). Data in Tabel 1.

\section{DFT resultate}

Figuur 4 dui aan dat daar 'n duidelike verwantskap is tussen die elektronskenkende krag van die R-sygroepe $\left(\mathrm{R}^{1}\right.$ en $R^{2}$ ) op die $\beta$-diketone, $\mathrm{R}^{1} \mathrm{COCHC}(\mathrm{OH}) \mathrm{R}^{2}, \mathbf{1}-\mathbf{1 5}$, en die reduksiepotensiaal $E_{p k}$ van die $\beta$-diketone. Aromatiese en estergroepe lei egter tot 'n afwyking van die lineêre verwantskap wat verkry word as slegs $\beta$-diketone met alifatiese en $\mathrm{CF}_{3}$-groepe, wat 'n suiwer induktiewe effek het, oorweeg word. Die gekombineerde induktiewe en resonansie-effek van die R-sygroepe in 1 - 15 op die reduksiepotensiaal $E_{\mathrm{pk}^{\prime}}$ kan egter teoreties bepaal word deur gebruik te maak van digtheidsfunksionaalteorie berekende energieë. Figuur 6 illustreer die goeie lineêre verwantskap wat verkry is tussen reduksiepotensiaal $E_{\mathrm{pk}}$ van die $\beta$-diketone 1 - 15, en digtheidfunksionaalteorieberekende (DFT-berekende) energieë van die laagste ongevulde molekulêre orbitaal energieë $\left(E_{\text {LOMO }}\right)\left(R^{2}=0.97\right.$ vir<smiles>C=COC(=O)C=C(C)O</smiles>

FIGUUR 5: Elektronskenking via enkelpaarresonansie in $\beta$-diketoon 13, wat lei tot meer elektrondigtheid op die $\beta$-diketoon se ruggraat.

gasfase berekeninge met die GGA OLYP funksionaal en 0.98 vir berekeninge met $\mathrm{CH}_{3} \mathrm{CN}$ as oplosmiddel). Daar bestaan 'n duidelike verband tussen $E_{\mathrm{pk}}$ en die berekende $E_{\text {LOMO }}$ binne die reeks van hierdie studie. Soortgelyke goeie akkuraatheid is verkry deur gebruik te maak van die hibried B3LYP funksionaal: $\mathrm{R}^{2}=0.99$ vir die gasfase berekeninge en 0.97 vir berekeninge met $\mathrm{CH}_{3} \mathrm{CN}$ as 'n oplosmiddel. Die energie van die LOMO, die orbitaal waarby die elektron bygevoeg word tydens reduksie, beïnvloed dus die redokschemie. Die uitstekende interafhanklikheid van $E_{\mathrm{pk}}$ vs $E_{\mathrm{LOMO}}$ maak die voorspelling van die reduksiepotensiaal van $\beta$-diketone moontlik met hoë akkuraatheid, gebaseer op LOMO energieë.

Die verwantskappe verkry uit die DFT berekeninge wat die eksperimentele oplosmiddel $\left(\mathrm{CH}_{3} \mathrm{CN}\right)$ in ag neem (in plaas van die gasfase), toon 'n soortgelyke akkuraatheid vir die lineêrepassing soos verkry vir die gasfase berekeninge. Die helling van die reduksiepotensiaal vs $\mathrm{E}_{\text {LOMO }}$ verwantskap is egter steiler vir die oplosmiddelberekeninge en beweeg na die ideale teoretiese helling van -1, veral vir die OLYP/TZP / $\mathrm{CH}_{3} \mathrm{CN}$ berekeninge waar die helling $1.04(4) \mathrm{e}^{-1}$ is. Die teoretiese helling vir reduksiepotensiaal $v s \mathrm{E}_{\mathrm{LOMO}}$ verwantskappe is -1 , omdat die LOMO-energie direk verband hou met die absolute redokspotensiaal (Perdew en Levy 1997, Casida 1999; Hamel et al., 2002, Cardona et al., 2011). Dit impliseer

TABEL 1: Reduksiespotensiaal $\left(\boldsymbol{E}_{\mathrm{pk}}\right.$ in $\mathrm{V}$ vs $\mathrm{FcH} / \mathrm{FcH}^{+}$), groepelektronegatiwiteite (Gordy-skaal) en Hammett-meta-substituent $\sigma$ konstantes van die aangeduide $\beta$-diketone $\mathrm{R}^{1} \mathrm{COCHC}(\mathrm{OH}) \mathrm{R}^{2}$.

\begin{tabular}{|c|c|c|c|c|c|c|c|c|c|}
\hline & $\mathbf{R}^{1}$ & $\mathbf{R}^{2}$ & $\mathrm{E}_{\mathrm{pk}} / \mathrm{V}$ & $\chi \mathrm{R}^{\mathrm{a}}$ & $\chi \mathrm{R}^{2}{ }^{\mathrm{a}}$ & $\chi \mathrm{R} 1+\chi \mathrm{R} 2$ & $\sigma_{\mathrm{R} 1^{\mathrm{b}}}$ & $\sigma_{\mathrm{R} 2{ }^{b}}$ & $\sigma_{\mathrm{R} 1}+\sigma_{\mathrm{R} 2}$ \\
\hline 1 & $\mathrm{CF}_{3}$ & $p-\mathrm{C}_{6} \mathrm{H}_{4} \mathrm{NO}_{2}$ & -1.045 & 3.01 & - & - & 0.43 & - & - \\
\hline 2 & $\mathrm{CF}_{3}$ & $\mathrm{CF}_{3}$ & -1.243 & 3.01 & 3.01 & 6.02 & 0.43 & 0.43 & 0.86 \\
\hline 3 & $\mathrm{CF}_{3}$ & Th & -1.541 & 3.01 & 2.10 & 5.11 & 0.43 & 0.09 & 0.52 \\
\hline 4 & $\mathrm{C}_{6} \mathrm{H}_{5}$ & $\mathrm{CF}_{3}$ & -1.564 & 3.01 & 2.21 & 5.22 & 0.06 & 0.43 & 0.49 \\
\hline 5 & $\mathrm{CF}_{3}$ & $\mathrm{CH}_{3}$ & -1.851 & 3.01 & 2.34 & 5.35 & 0.43 & -0.069 & 0.361 \\
\hline 6 & $\mathrm{CF}_{3}$ & $\mathrm{C}\left(\mathrm{CH}_{3}\right)_{3}$ & -1.889 & 3.01 & 2.27 & 5.28 & 0.43 & -0.10 & 0.33 \\
\hline 7 & Th & Th & -1.857 & 2.10 & 2.10 & 4.20 & 0.09 & 0.09 & 0.18 \\
\hline 8 & Th & $\mathrm{Ph}$ & -1.884 & 2.10 & 2.21 & 4.31 & 0.06 & 0.09 & 0.15 \\
\hline 9 & $\mathrm{Ph}$ & $\mathrm{Ph}$ & -1.934 & 2.21 & 2.21 & 4.42 & 0.06 & 0.06 & 0.12 \\
\hline 10 & $\mathrm{CH}_{3}$ & $\mathrm{CH}_{3}$ & -2.618 & 2.34 & 2.34 & 4.68 & -0.069 & -0.069 & -0.138 \\
\hline 11 & $\mathrm{C}_{6} \mathrm{H}_{5}$ & $\mathrm{CH}_{3}$ & -2.138 & 2.34 & 2.21 & 4.55 & 0.06 & -0.069 & -0.009 \\
\hline 12 & $\mathrm{C}\left(\mathrm{CH}_{3}\right)_{3}$ & $\mathrm{C}\left(\mathrm{CH}_{3}\right)_{3}$ & -2.748 & 2.27 & 2.27 & 4.54 & -0.10 & -0.10 & -0.20 \\
\hline 13 & $\mathrm{CH}_{3}$ & $\mathrm{OCH}_{3}$ & -3.017 & 2.34 & 2.68 & 5.02 & -0.069 & 0.12 & 0.051 \\
\hline 14 & $\mathrm{CF}_{3}$ & $\mathrm{C}_{4} \mathrm{H}_{2} \mathrm{~S}-\mathrm{C}_{4} \mathrm{H}_{3} \mathrm{~S}$ & -1.470 & 3.01 & - & - & 0.43 & - & - \\
\hline 15 & $\mathrm{CF}_{3}$ & $\mathrm{Fu}$ & -1.581 & 3.01 & 2.230 & 5.240 & 0.43 & 0.06 & 0.49 \\
\hline
\end{tabular}

a) Die groepelektronegatiwiteit uit verwysings: du Plessis et al. 1998, Kagarise 1955, Conradie et al. 2008, Klaas 2002, Conradie en Conradie 2015.

b) Die Hammett-meta-substituent $\sigma$-konstantes uit verwysings: Hammett 1935, Hammett 1937, Hansch et al. 1991. 
dat die produk van $\mathrm{E}_{\text {LOMO }}$ met die elektronlading (-1) 'n absolute redokspotensiaal in $\mathrm{eV}$ gee. Die $\mathrm{y}$-as afsnit van die reduksiepotensiaal vs $\mathrm{E}_{\text {LOMO }}$ grafiek, vermenigvuldig met die elektronlading (-1), gee die absolute redokspotensiaal van die eksperimentele verwysingstelsel - naamlik van die ferroseen redokskoppel $\mathrm{FcH} / \mathrm{FcH}^{+}$. Hoë vlak ab initio molekulêre orbitaalteorie verwysingspunt berekende waardes vir die absolute redokspotensiaal van die ferroseen redokskoppeling in asetonitriel is $4.988 \mathrm{~V}$ (wanneer bereken word op die G3(MP2)-RAD-Full-TZ vlak, met behulp van gasfase energie en COSMO-RS solvasie energieë) (Namazian et al. 2010) en $+4.97 \mathrm{~V}$ (wanneer bereken word op die SMDB3LYP-D2 / def2-QZVPPD / / B3LYP / LanL2TZf / 631G(d) vlak) (Romańczyk et al. 2014). Hier het ons 4.97(11) eV metbehulp van die OLYP/TZP/ $\mathrm{CH}_{3} \mathrm{CNDFT}$ berekeninge verkry. Absolute redokspotensiale van $\beta$-diketone kan dus verkry word deur $-E_{\mathrm{LOMO}}$ (in $\mathrm{eV}$ ) met behulp van OLYP/ $\mathrm{TZP} / \mathrm{CH}_{3} \mathrm{CN}$ berekeninge. Resultate van soortgelyke akkuraatheid word deur albei funksionele (B3LYP en OLYP) verkry wanneer relatiewe energie benodig word (soortgelyke $\mathrm{R}^{2}$-waardes). Wanneer absolute redokspotensiaal benodig word, het die OLYP / TZP / $\mathrm{CH}_{3} \mathrm{CN}$ DFT-berekeninge egter die akkuraatse resultate gelewer.
Tydens die reduksieproses word die elektron by die LOMO van die $\beta$-diketoon bygevoeg. Die LOMO van geselekteerde $\beta$-diketone word in Figuur 7 getoon, waar die lokus van die bygevoegde elektron gevisualiseer word deur die spindigtheidsdiagram van die gereduseerde $\beta$-diketoon. Die vorm van die spindigtheidsdiagram van 'n spesifieke $\beta$-diketoon-anioon is soortgelyk aan die vorm van die LOMO van die neutrale $\beta$-diketoon. Evaluering van die spindigtheidsdiagramme toon die effek van induktiewe en aromatiese groepe op die lokus van die ongepaarde elektron. Figuur 7 dui aan dat die ongepaarde elektron se digtheid van die gereduseerde $\beta$-diketoon oor die aromatiese kern van die $\beta$-diketonato-anioon versprei is en ook oor aromatiese R-groepe verleng word indien aanwesig. Die elektrondigtheid op die pseudo-aromatiese ruggraat van die $\beta$-diketoon neem af namate meer R-groepe aromaties word. $\beta$-diketone $2^{-}, 5^{-}, \mathbf{6}^{-}, \mathbf{1 0}^{-}$en $12^{-}$wat twee alifatiese groepe bevat, het gemiddeld ongeveer $90 \%$ spindigtheid op die $\beta$-diketoon-ruggraat $(\mathrm{C}(\mathrm{OH}) \mathrm{CHCO})$. $\beta$-Diketone $1^{-}, \mathbf{2}^{-}, \mathbf{4}^{-}, \mathbf{1 1}^{-}, 14^{-}$en $15^{-}$met een aromatiese en een alifatiese groep het egter gemiddeld ongeveer $55 \%$ spindigtheid op die $\beta$-diketoon-ruggraat $(\mathrm{COCHC}(\mathrm{OH}))$ en $30-60 \%$ op die aromatiese groep. $\beta$-diketone $7^{-}, 8^{-}, 9^{-}$and $15^{-}$met twee aromatiese groepe het gemiddeld net meer as

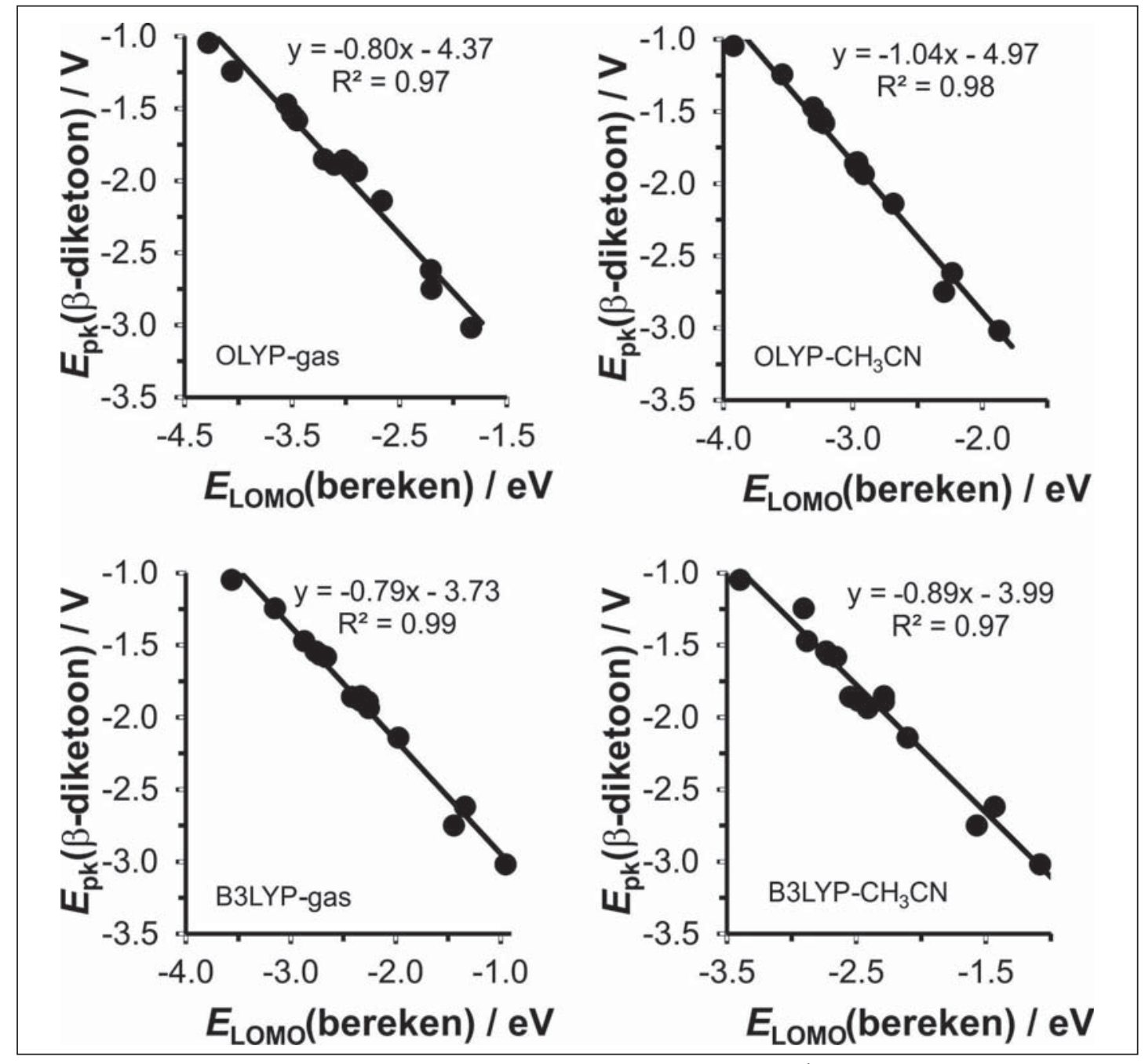

FIGUUR 6: Die verwantskappe tussen die eksperimentele reduksiepotensiaal $\left(E_{\mathrm{pk}}\right.$ in $\left.\mathrm{V} v \mathrm{FcH} / \mathrm{FcH}^{+}\right)$van $\beta$-diketone 1 - 15 en die DFT bereken LOMO-energie. Data in Ondersteunende inligting Tabel S1. 
$50 \%$ spindigtheid op die $\beta$-diketoon-ruggraat $(\mathrm{COCHC}(\mathrm{OH}))$ en $15-30 \%$ op elke aromatiese groep. Die groot hoeveelheid spindigtheid van $61 \%$ is op die $p-\mathrm{C}_{6} \mathrm{H}_{4}-\mathrm{NO}_{2}$-groep van $\mathbf{1}^{-}$, en spruit uit 'n kombinasie van die effek van 'n elektrononttrekkende groep $\left(\mathrm{NO}_{2}\right)$ en 'n aromatiese groep (feniel).

Die Molekulêre Elektrostatiese Potensiaal (MESP) oppervlak van geselekteerde molekules word geillustreer in Figuur 8. Die elektrostatiese potensiaal V(r) waardes bied die positiewe en negatief- gelaaide elektrostatiese potensiaal in die molekule. Die MESP-oppervlak in die buitenste gebied van 'n molekule dui aan hoe laasgenoemde 'gesien' word deur 'n naderende reaktant. Die teken van elektrostatiese potensiaal in 'n oppervlaksgebied word bepaal deur die oorheersing van bydrae tot negatiewe ladings of bydrae tot positiewe ladings. Gevolglik stel die blou kleur die positiewe gebied voor en is dit geneig tot nukleofiele aanval, die rooi kleur toon die negatiewe gebied wat die elektrofiliese aanval bevoordeel, terwyl groen neutraal is. Die MESP-oppervlak van die neutrale $\beta$-diketone is groen tot ligblou, wat daarop dui dat dit effens geneig is tot nukleofiele aanval, d.w.s. kan gereduseer word. Aan die ander kant is die MESP-oppervlak van die gereduseerde $\beta$-diketone geel tot rooi, wat die oortollige negatiewe lading op die $\beta$-diketone illustreer. Die negatiewe gebied van $\beta$-diketoon $\mathbf{1 0}^{-}$, met twee alifatiese groepe, word gekonsentreer oor die $\beta$-diketoon-ruggraat $(\mathrm{COCHC}(\mathrm{OH}))$, terwyl die negatiewe gebied van $\beta$-diketoon $\mathbf{1 1}^{-}$, met een aromatiese en een alifatiese groep, gekonsentreer is op beide die $\beta$-diketoon ruggraat en die aromatiese groep. Die negatiewe gebied van $\beta$-diketoon $9^{-}$met twee aromatiese groepe, word deur die hele molekule versprei. 'n Algemene neiging word waargeneem dat die elektrostatiese potensiaal op die enol-O-atoom afneem (minder negatief) namate die eksperimentele reduksiepotensiaal van die $\beta$-diketoon minder negatief word, sien Figuur 9. $\beta$-Diketoon 1 met die positiefste reduksiepotensiaal, het ook die kleinste elektrostatiese potensiaal van enol-O-atoom, $\mathrm{V}_{\mathrm{O}-\mathrm{enol}}$.'n Soortgelyke neiging word waargeneem vir die elektrostatiese potensiaal van die karboniel-O-atoom.

\begin{tabular}{|c|c|c|c|}
\hline & $\begin{array}{l}\text { 10: geen aromatiese } \\
\text { groep nie }\end{array}$ & $\begin{array}{l}\text { 11: een aromatiese } \\
\text { groep }\end{array}$ & $\begin{array}{l}\text { 9: twee aromatiese } \\
\text { groepe }\end{array}$ \\
\hline $\begin{array}{l}\text { LOMO neutraal } \\
\beta \text {-diketoon }\end{array}$ & & & \\
\hline $\begin{array}{l}\text { spindigtheidsdiagram } \\
\beta \text {-diketoon }\end{array}$ & & & \\
\hline $\begin{array}{l}\text { \% spin verspreiding } \\
\mathrm{R}^{1}:(\mathrm{C}(\mathrm{OH}) \mathrm{CHCO}): \mathrm{R}^{2}\end{array}$ & $3: 93: 4$ & $1: 59: 40$ & $27: 55: 18$ \\
\hline
\end{tabular}

FIGUUR 7: B3LYP / 6-311G (d, p) LOMO's van die neutrale $\beta$-diketone 9 - 11 en spindigtheidsdiagramme van die gereduseerde $\beta$-diketone 9- -11 : OLYP / TZP LOMO's / spindiagramme (nie getoon nie) is soortgelyk in vorm. ' $\mathrm{n}$ Kontoer van 0.05 en $0.005 \mathrm{e} / \AA^{3}$ is onderskeidelik vir die MO en spindiagramme gebruik.

\begin{tabular}{|c|c|c|c|}
\hline $\begin{array}{c}\text { Neutrale } \\
\beta \text {-diketoon }\end{array}$ & & \\
$\begin{array}{c}\text { Gereduseerde } \\
\beta \text {-diketoon }\end{array}$ & $\begin{array}{c}\text { 10: geen aromatiese } \\
\text { groep nie }\end{array}$ & $\begin{array}{c}\text { 11: een aromatiese } \\
\text { groep }\end{array}$ & $\begin{array}{c}\text { 9: twee aromatiese } \\
\text { groepe }\end{array}$ \\
\hline-0.15 & &
\end{tabular}

FIGUUR 8: Molekulêre Elektrostatiese Potensiaal (MESP) oppervlak van die aangeduide neutrale en gereduseerde $\beta$-diketone. 


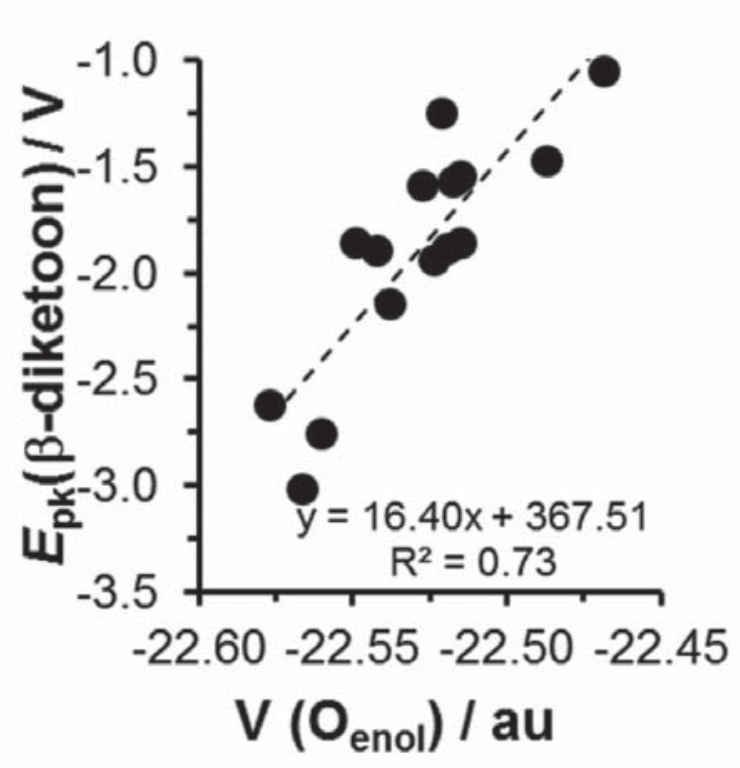

FIGUUR 9: Die korrelasie tussen die eksperimentele reduksiepotensiaal ( $E_{\mathrm{p}}$ in $\mathrm{V}$ vs $\mathrm{FcH} / \mathrm{FcH}^{+}$) en die MESP atoompotensiaal van die enol-O-atome van gereduseerde $\beta$-diketone 1 - -15 .

\section{Gevolgtrekking}

Die reduksiepotensiaal van $\beta$-diketone, $\mathrm{R}^{1} \mathrm{COCHC}(\mathrm{OH}) \mathrm{R}^{2}$, wat alifatiese $\mathrm{R}$-groepe bevat met hoofsaaklik $\sigma$ induktiewe effek $\left(\mathrm{R}=\mathrm{CH}_{3}, \mathrm{C}\left(\mathrm{CH}_{3}\right)_{3}\right.$ of $\left.\mathrm{CF}_{3}\right)$, hou lineêr verband met die die somtotaal van elektronskenkende (of elektrononttrekkende) effek van die R-groepe wanneer dit uitgedruk word in terme van Hammett-konstant $\left(\sigma_{R 1}+\sigma_{R 2}\right)$ of groepelektronegatiwiteite $\left(\chi_{R 1}+\chi_{R 1}\right)$ van die betrokke R-groepe. Die effek van 'n aromatiese R-groep op die reduksiepotensiaal van $\beta$-diketone is egter ' $n$ wisselwerking tussen die induktiewe effek deur die $\sigma$-stelsel en 'n resonansieeffek deur die $\pi$-stelsel, wat lei tot ' $n$ minder negatiewe reduksiepotensiaal as wat verwag word (verbinding word makliker gereduseer) teenoor wat die geval is as slegs die induktiewe effek teenwoordig is. Aan die ander kant lei elektronskenking via alleenpaarresonansie (op O van estergroep $\mathrm{R}=\mathrm{OCH}_{3}$ ) tot 'n meer negatiewe reduksiepotensiaal as wat verwag word as gevolg van 'n suiwer induktiewe effek as gevolg van toenemende elektrondigtheid op die ruggraad van die $\beta$-diketoon. Die DFT-berekende energie van die LOMO van die $\beta$-diketone weerspieël die gekombineerde induktiewe en resonansie-effek van die R-sygroepe van $\beta$-diketone. Dit word aangetoon deur die lineêre verwantskap wat verkry is tussen die reduksiepotensiaal $E_{p k}$ van die $\beta$-diketone en die digtheidfunksionaalteorieberekende (DFT-berekende) energieë van die laagste ongevulde molekulêre orbitaal ( $\left.E_{\text {Lомо }}\right)$ met $\mathrm{R}^{2}=0.97$ - 0.99 , afhangende van die DFT-metode wat gebruik is.

\section{Outeursbydrae}

JC en MMC het die projek gekonseptualiseer. NGSM het die eksperimentele en berekeningswerk onder toesig van JC en MMC gedoen. NGSM was verantwoordelik vir die opstel van die publikasie, met hersiening en redigering deur JC en MMC.

\section{Ondersteunende inligting}

Tabelle S1 - S3 en geoptimiseerde koördinate van die DFT berekeninge word in die Ondersteunende Inligting verskaf.

\section{Erkenning}

Hierdie werk het ondersteuning ontvang van die SuidAfrikaanse Nasionale Navorsingstigting (Beurs-nommers 113327, 96111 (JC) en 108960 (MMC)) en die Sentrale Navorsingsfonds van die Universiteit van die Vrystaat, Bloemfontein, Suid-Afrika. Die UV se hoëverwerkingsrekenaarfasiliteit word erken vir rekenaartyd.

\section{Verwysings}

Buchta, RC, Evans DH. 1968. Electrochemical reduction of beta-diketones in dimethylsulfoxide. Analytical Chemistry 40, 2181-2186.

Buchta RC, Evans DH. 1970. Mechanism of the electrochemical reduction of enolized 1,3-diketones, Journal of the Electrochemical Society: Electrochemical Science 117, 1494-1500.

Cardona CM, Li W, Kaifer AE, Stockdale D, Bazan GC. 2011. Electrochemical considerations for determining absolute frontier orbital energy levels of conjugated polymers for solar cell applications. Advanced Materials 23, 23672371.

Casida ME. 1999. Correlated optimized effective-potential treatment of the derivative discontinuity and of the highest occupied Kohn-Sham eigenvalue: A Janak-type theorem for the optimized effective-potential model. Physical Review B: Condensed Matter 59, 4694-4698.

Conradie MM, Conradie J. 2015. Electrochemical behaviour of Tris( $\beta$-diketonato) iron(III) complexes: A DFT and experimental study. Electrochimica Acta 152, 512-519.

Conradie MM, Muller AJ, Conradie J. 2008. Thienyl-containing $\beta$-diketones: Synthesis, characterisation, crystal structure and keto-enol kinetics. South Synthesis, characterisation, crystal st
African Journal of Chemistry $61,13-21$.

Du Plessis WC, Vosloo TG, Swarts JC. 1998. $\beta$-Diketones containing a ferrocenyl group: synthesis, structural aspects, pKa' values, group electronegativities and complexation with rhodium(I). Dalton Transactions 15, 2507-2514.

Evans DH. O'Connell KM, Petersen RA, Kelly MJ. 1983. Cyclic voltammetry. Journal of Chemical Education 60, 290-293.

Frisch MJ, Trucks GW, Schlegel HB, Scuseria GE, Robb MA, Cheeseman JR, et al. Gaussian, Inc., Wallingford CT, 2016. Gaussian 16, Revision B.01.

Gadre SR, Shirsat RN. 2000. Electrostatics of Atoms and Molecules. Universities Press, India.

Gritzner G, Kuta J. 1984. Recommendations on reporting electrode potentials in nonaqueous solvents. Pure and Applied Chemistry 56, 461-466.

Gschneidner Jr. KA, Bünzli J-CG, Pecharsky VK. 2005. Handbook on the Physics and Chemistry of Rare Earths, Volume 35, Elsevier.

Hamel S, Duffy P, Casida ME, Salahub DR. 2002. Kohn-Sham orbitals and orbital energies: fictitious constructs but good approximations all the same. Journal of Electron Spectroscopy Related Phenomena 123, 345-363.

Hammett LP. 1935. Some relations between reaction rates and equilibrium constants. Chemical Reviews 17, 125-136.

Hammett LP. 1937. The effect of structure upon the reactions of organic compounds. Benzene derivatives. Journal of the American Chemical Society 59, 96-103.

Hansch C, Leo A, Taft RW. 1991. A survey of Hammett substituent constants and resonance and field parameters. Chemical Reviews 91, 165-195.

Kagarise RE. 1955. Relation between the electronegativities of adjacent substitutents and the stretching frequency of the carbonyl group. Journal of the American Chemical Society 77, 1377-1379.

Katritzky AR, Wang Z, Wang M, Wilkerson CR, Hall CD, Akhmedov NG. 2004 Preparation of $\beta$-Keto esters and $\beta$-Diketones by $C$-acylation/deacetylation of acetoacetic esters and acetonyl ketones with 1-Acylbenzotriazoles. Journal of Organic Chemistry 69, 6617-6622.

Klaas P. 2002. Synthesis, electrochemical, kinetic and thermodynamic properties of new ferrocene-containing beta-diketonato rhodium(I) complexes with biomedical applications, M.Sc. Thesis, University of the Free State. 
Klamt A. 1995. Conductor-like screening model for real solvents: A new approach to the quantitative calculation of solvation phenomena. Journal of Physical Chemistry 99, 2224-2235.

Klamt A, Jones V. 1996. Treatment of the outlying charge in continuum solvation models. Journal of Chemical Physics 105, 9972-9981.

Klamt A, Schüürmann G. 1993. COSMO: A new approach to dielectric screening in solvents with explicit expressions for the screening energy and its gradient. Journal of the Chemical Society, Perkin Transactions 2 5, 799-805.

Kuhn A, Von Eschwege KG, Conradie J. 2011. Electrochemical and DFT-modeled reduction of Enolized 1,3-Diketones. Electrochimica Acta 56, 6211-6218.

Marenich AV, Cramer CJ, Truhlar DG. 2009. Universal solvation model based on solute electron density and on a continuum model of the solvent defined by the bulk dielectric constant and atomic surface tensions. Journal of Physical Chemistry B 113, 6378-6396

McDaniel DH, Brown HC. 1958. An extended table of Hammett substituen constants based on the ionization of substituted benzoic acids. Journal of Organic Chemistry 23, 420-427.

Namazian M, Lin CY, Coote ML. 2010. Benchmark calculations of absolute reduction potential of Ferricinium/Ferrocene couple in nonaqueous solutions. Journal of Chemical Theory and Computation 6, 2721-2725.

Neal TE, Murray RW. 1970. Autocatalysis of the kinetic wave of acetylacetone in acetonitrile solvent. Analytical Chemistry 42, 1654-1656.

Perdew JP, Levy M. 1997. Significance of the highest occupied Kohn-Sham eigenvalue. Physical Review B: Condensed Matter 56, 16021-16028.
Pombeiro AJL. 2005. Electron-donor/acceptor properties of carbynes, carbenes, vinylidenes, allenylidenes and alkynyls as measured by electrochemical ligand parameters. Journal of Organometallic Chemistry 690, 6021-6040.

Romańczyk PP, Rotko G, Kurek SS. 2014. The redox potential of the phenyl radical/ anion couple and the effect there on of the lithium cation: A computational study. Electrochemistry Communications 48, 21-23.

Sawyer DT, Roberts Jr. JL. 1974. Experimental electrochemistry for chemists. John Wiley \& Sons, New York.

Skyner RE, McDonagh JL, Groom CR, Van Mourik T, Mitchell JBO. 2015. A review of methods for the calculation of solution free energies and the modelling of systems in solution. Physical Chemistry Chemical Physics 17, 6174-6191.

Stary J. 1964. The solvent extraction of metal chelates, first ed. MacMillan, New York.

Te Velde G, Bickelhaupt FM, Baerends EJ, Fonseca Guerra C, Van Gisbergen SJA Snijders JG, Ziegler T. 2001. Chemistry with ADF, Journal of Computational Chemistry 22, 931-967.

Vigato PA, Peruzzo V, Tamburini S. 2009. The evolution of $\beta$-diketone or $\beta$-diketophenol ligands and related complexes. Coordination Chemistry Reviews 253, 1099-12 01.

Wells PR. 1968. Progress in Physical Organic Chemistry, John Wiley \& Son Inc., New York, pp. 111-145. 


\title{
Reduksiepotensiaal van $\beta$-diketoon: Die effek van elektronskenkende, aromatiese en estersubstituentgroepe
}

\author{
Ondersteunende inligting \\ Geoptimiseerde Cartesiese Koördinate (Å)
}

Al die verbindings is geoptimiseer met behulp van die OLYP funksionaal in gasfase, met die trippel- $\zeta$-basisstel TZP.

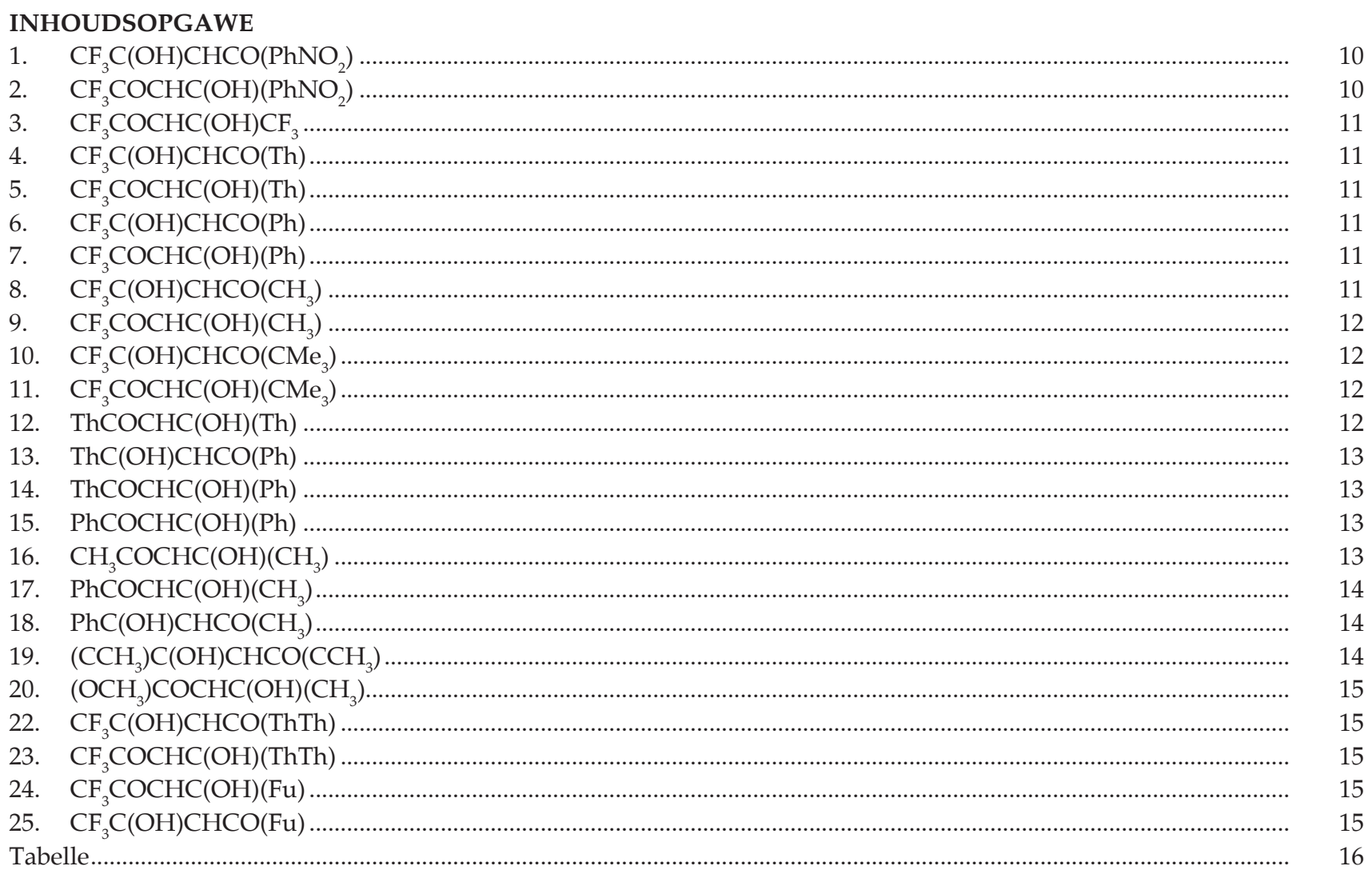

\begin{tabular}{|c|c|c|c|c|c|c|c|}
\hline \multirow[t]{2}{*}{1.} & \multicolumn{3}{|c|}{$\mathrm{CF}_{3} \mathrm{C}(\mathrm{OH}) \mathrm{CHCO}\left(\mathrm{PhNO}_{2}\right)$} & $\mathrm{F}$ & 3.705100000 & -1.967637000 & 0.062385000 \\
\hline & & & & $\mathrm{F}$ & 4.919247000 & -0.516226000 & -1.063894000 \\
\hline $\mathrm{C}$ & -0.866198000 & 0.501604000 & -0.021758000 & $\mathrm{~F}$ & 4.896104000 & -0.461328000 & 1.139838000 \\
\hline $\mathrm{C}$ & -1.854584000 & 1.503537000 & 0.016472000 & $\mathrm{~N}$ & -5.039453000 & -0.522608000 & 0.021921000 \\
\hline C & -1.282603000 & -0.843276000 & -0.049350000 & $\mathrm{O}$ & -5.855797000 & 0.406405000 & 0.050080000 \\
\hline $\mathrm{H}$ & -1.547779000 & 2.544696000 & 0.035618000 & $\mathrm{O}$ & -5.328449000 & -1.725832000 & 0.008485000 \\
\hline $\mathrm{H}$ & -0.563680000 & -1.654763000 & -0.086693000 & $\mathrm{O}$ & 3.340961000 & 1.583438000 & -0.038266000 \\
\hline $\mathrm{C}$ & -3.208406000 & 1.180683000 & 0.031148000 & $\mathrm{O}$ & 0.877802000 & 2.143923000 & -0.061181000 \\
\hline C & -2.633777000 & -1.180564000 & -0.037521000 & $\mathrm{H}$ & 2.447087000 & 2.092818000 & -0.055891000 \\
\hline $\mathrm{H}$ & -3.970897000 & 1.952127000 & 0.062121000 & $\mathrm{H}$ & 1.424324000 & -1.138792000 & 0.038370000 \\
\hline $\mathrm{H}$ & -2.953671000 & -2.216988000 & -0.060767000 & & & & \\
\hline $\mathrm{C}$ & -3.584825000 & -0.162780000 & 0.004705000 & 2. & $\mathrm{CF}_{3} \mathrm{COCHC}(\mathrm{C}$ & $\mathrm{hNO}_{2}$ ) & \\
\hline $\mathrm{C}$ & 0.585305000 & 0.916036000 & -0.031371000 & & & & \\
\hline C & 1.639123000 & -0.081473000 & 0.002847000 & $\mathrm{C}$ & -0.853400000 & 0.448780000 & 0.075133000 \\
\hline $\mathrm{C}$ & 2.950208000 & 0.319849000 & -0.002490000 & $\mathrm{C}$ & -1.810092000 & 1.450834000 & -0.177135000 \\
\hline $\mathrm{C}$ & 4.128030000 & -0.671735000 & 0.034248000 & $\mathrm{C}$ & -1.297289000 & -0.871689000 & 0.280013000 \\
\hline
\end{tabular}




$\begin{array}{lrrr}\mathrm{H} & -1.484976000 & 2.473425000 & -0.337787000 \\ \mathrm{H} & -0.591618000 & -1.665406000 & 0.506159000 \\ \mathrm{C} & -3.166222000 & 1.147690000 & -0.232090000 \\ \mathrm{C} & -2.652701000 & -1.183586000 & 0.235900000 \\ \mathrm{H} & -3.904351000 & 1.917080000 & -0.431388000 \\ \mathrm{H} & -3.000713000 & -2.196624000 & 0.407229000 \\ \mathrm{C} & -3.574458000 & -0.168418000 & -0.021097000 \\ \mathrm{C} & 0.581929000 & 0.819794000 & 0.136259000 \\ \mathrm{C} & 1.637691000 & -0.065488000 & -0.051007000 \\ \mathrm{C} & 2.981870000 & 0.412866000 & 0.015839000 \\ \mathrm{C} & 4.152016000 & -0.623094000 & -0.168232000 \\ \mathrm{~F} & 4.531373000 & -1.107897000 & 1.054418000 \\ \mathrm{~F} & 3.781274000 & -1.695155000 & -0.935703000 \\ \mathrm{~F} & 5.231110000 & -0.051860000 & -0.749714000 \\ \mathrm{~N} & -5.034435000 & -0.496262000 & -0.061330000 \\ \mathrm{O} & -5.820706000 & 0.434341000 & -0.278032000 \\ \mathrm{O} & -5.358282000 & -1.675662000 & 0.127733000 \\ \mathrm{O} & 3.301744000 & 1.603069000 & 0.238493000 \\ \mathrm{O} & 0.810469000 & 2.110818000 & 0.366922000 \\ \mathrm{H} & 1.448561000 & -1.104532000 & -0.282393000 \\ \mathrm{H} & 1.826395000 & 2.198363000 & 0.361577000\end{array}$

3. $\mathrm{CF}_{3} \mathrm{COCHC}(\mathrm{OH}) \mathrm{CF}_{3}$

$\begin{array}{lr}\text { C } & 1.193361000 \\ \text { C } & -0.010841000 \\ \text { C } & -1.230815000 \\ \text { O } & 1.329412000 \\ \text { O } & -1.271621000 \\ \text { H } & -0.039117000 \\ \text { C } & 2.552205000 \\ \text { F } & 3.275043000 \\ \text { F } & 3.274018000 \\ \text { F } & 2.399413000 \\ \text { H } & 0.382830000 \\ \text { C } & -2.584443000 \\ \text { F } & -3.659530000 \\ \text { F } & -2.651724000 \\ \text { F } & -2.652828000\end{array}$

$-0.000034000$

$-0.000182000$

0.000023000

0.000307000

0.000425000

$-0.000560000$

$-0.000169000$

$-1.101820000$

1.102893000

$-0.001554000$

0.000381000

$-0.000128000$

$-0.001261000$

$-1.103334000$

1.104210000
$\begin{array}{lr}\mathrm{O} & 0.533666000 \\ \mathrm{H} & -0.535134000\end{array}$

H -1.020411000

1.849311000

$-1.311426000$

2.044544000

\section{5. $\mathrm{CF}_{3} \mathrm{COCHC}(\mathrm{OH})(\mathrm{Th})$}

$-1.462000000$

$-0.118972000$

0.891012000

$-0.477965000$

$-1.664818000$

$-2.274833000$

$-0.339734000$

$-2.641708000$

0.486079000

$-0.241353000$

0.448920000

$-0.384977000$

$-0.093581000$

$-1.738397000$

$-0.093622000$

1.700331000

1.819324000

$-1.321719000$

2.059818000
$-0.000090000$

$-0.000745000$

$-0.000618000$

$-0.000095000$

$-0.000011000$

0.000154000

0.000144000

$-0.000014000$

$-0.000225000$

0.000240000

$-0.000067000$

$-0.000057000$

$-0.000072000$

0.000034000

0.000084000

$-1.102670000$

0.000049000

1.102921000

0.000207000

$-0.000131000$

$-0.000087000$

$-0.000393000$

\section{4. $\mathrm{CF}_{3} \mathrm{C}(\mathrm{OH}) \mathrm{CHCO}(\mathrm{Th})$}

$\begin{array}{lr}\text { C } & 2.251347000 \\ \text { C } & 1.929101000 \\ \text { S } & 3.379086000 \\ \text { C } & 4.373288000 \\ \text { C } & 3.641680000 \\ \text { H } & 1.515578000 \\ \text { H } & 5.453212000 \\ \text { H } & 4.090270000 \\ \text { C } & 0.615741000 \\ \text { C } & -0.587788000 \\ \text { C } & -1.811212000 \\ \text { C } & -3.131317000 \\ \text { F } & -3.876606000 \\ \text { F } & -2.923446000 \\ \text { F } & -3.875793000 \\ \text { O } & -1.988998000\end{array}$

$-0.000367000$ $-0.000539000$ 0.000968000 0.000683000 0.000290000 $-0.000840000$ 0.001163000 0.000368000 $-0.001282000$ $-0.000767000$ $-0.000044000$ 0.000507000 $-1.101398000$ 0.000551000 1.102893000 0.000179000
0.739664000 $-0.145396000$ 0.391009000 $-0.477237000$ $-0.224435000$ $-1.810140000$ $-0.218064000$ 1.689729000 1.993501000 $-1.219394000$ 2.092395000 0.181955000 1.074477000 $-1.200664000$ 0.601085000 $-1.672123000$ $-0.773969000$ 2.142363000 $-1.929858000$ 1.304891000 $-2.744592000$ $-1.144220000$

$-0.000005000$ 0.001689000 $-0.000269000$ 0.001308000 $-1.102467000$ 0.005463000 1.102226000 $-0.003863000$ $-0.003480000$ 0.004697000 $-0.004078000$ 0.000050000 0.002326000 $-0.002463000$ 0.002510000 $-0.002594000$ 0.000047000 0.004153000 $-0.004871000$ 0.004516000 $-0.004802000$ 0.000071000

\section{7. $\mathrm{CF} 3 \mathrm{COCHC}(\mathrm{OH})(\mathrm{Ph})$}

$\begin{array}{lr}\text { C } & 0.580909000 \\ \text { C } & -0.561082000 \\ \text { C } & -1.848272000 \\ \text { C } & -3.116003000 \\ \text { F } & -3.928548000\end{array}$

$-0.095996000$ 0.022672000 $-0.031356000$ 0.099128000 $-0.982562000$ 


$\begin{array}{lrrr} & & & \\ \text { F } & -2.805093000 & -1.783530000 & 0.189822000 \\ \text { O } & -3.830057000 & -0.126137000 & 1.213962000 \\ \text { O } & -2.062016000 & 1.695511000 & -0.173991000 \\ \text { H } & -0.467105000 & 1.974690000 & -0.252151000 \\ \text { C } & 1.967540000 & 0.145709000 & -0.048122000 \\ \mathrm{C} & 3.034076000 & 1.052099000 & 0.110887000 \\ \mathrm{C} & 2.263362000 & -1.227307000 & -0.161631000 \\ \mathrm{C} & 4.349325000 & 0.597883000 & 0.166303000 \\ \mathrm{C} & 3.580631000 & -1.675452000 & -0.110207000 \\ \mathrm{C} & 4.628638000 & -0.766187000 & 0.057616000 \\ \mathrm{H} & 2.823674000 & 2.113033000 & 0.198276000 \\ \mathrm{H} & 1.470675000 & -1.954086000 & -0.310723000 \\ \mathrm{H} & 5.160127000 & 1.312210000 & 0.294938000 \\ \mathrm{H} & 3.791373000 & -2.738715000 & -0.206738000 \\ \mathrm{H} & 5.657370000 & -1.119575000 & 0.099300000 \\ \mathrm{H} & -0.537992000 & 2.150213000 & -0.248566000\end{array}$

\section{8. $\mathrm{CF}_{3} \mathrm{C}(\mathrm{OH}) \mathrm{CHCO}\left(\mathrm{CH}_{3}\right)$}

$\begin{array}{lr}\text { C } & 2.178784000 \\ \text { C } & 0.835889000 \\ \text { C } & -0.229644000 \\ \text { C } & -1.696025000 \\ \text { F } & -2.349268000 \\ \text { F } & -1.798318000 \\ \text { F } & -2.350129000 \\ \text { O } & -0.101281000 \\ \text { O } & 2.369681000 \\ \text { H } & 0.672279000 \\ \text { C } & 3.365802000 \\ \text { H } & 3.070017000 \\ \text { H } & 3.990473000 \\ \text { H } & 3.983781000 \\ \text { H } & 0.934585000\end{array}$

$$
\begin{array}{r}
-0.047440000 \\
-0.591129000 \\
0.273065000 \\
-0.194841000 \\
0.272239000 \\
-1.554122000 \\
0.271095000 \\
1.587548000 \\
1.200229000 \\
-1.661343000 \\
-0.987948000 \\
-2.040002000 \\
-0.784574000 \\
-0.793793000 \\
1.707426000
\end{array}
$$

$-0.000140000$

0.000126000

0.000616000

$-0.000126000$

$-1.102474000$

$-0.000869000$

1.102197000

0.001203000

0.000660000

$-0.000546000$

$-0.000801000$

$-0.007054000$

$-0.878199000$

0.883536000

0.001829000

\section{9. $\mathrm{CF}_{3} \mathrm{COCHC}(\mathrm{OH})\left(\mathrm{CH}_{3}\right)$}

$\begin{array}{lrr}\text { C } & 2.147098000 & -0.113628000 \\ \text { C } & 0.835549000 & -0.557345000 \\ \text { C } & -0.239632000 & 0.382535000 \\ \text { C } & -1.709405000 & -0.179641000 \\ \text { F } & -2.161228000 & -0.227327000 \\ \text { F } & -1.791013000 & -1.450454000 \\ \text { F } & -2.554520000 & 0.602257000 \\ \text { O } & -0.097880000 & 1.624918000 \\ \text { O } & 2.447345000 & 1.182808000 \\ \text { H } & 0.635797000 & -1.621495000 \\ \text { C } & 3.334922000 & -1.022801000 \\ \text { H } & 3.038191000 & -2.072800000 \\ \text { H } & 3.943701000 & -0.826292000 \\ \text { H } & 3.966112000 & -0.816405000 \\ \text { H } & 1.552448000 & 1.656223000\end{array}$

\section{0. $\mathrm{CF}_{3} \mathrm{C}(\mathrm{OH}) \mathrm{CHCO}\left(\mathrm{CMe}_{3}\right)$}

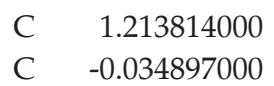

0.506550000

$-0.244864000$
0.867386000

$-0.004354000$

0.000308000

0.000419000

$\begin{array}{lr}\text { C } & -1.230390000 \\ \text { C } & -2.588810000 \\ \text { F } & -3.317853000 \\ \text { F } & -2.447035000 \\ \text { F } & -3.318705000 \\ \text { O } & -1.349142000 \\ \text { O } & 1.184120000 \\ \text { H } & -0.036979000 \\ \text { C } & 2.562799000 \\ \text { H } & -0.367879000 \\ \text { C } & 2.641828000 \\ \text { H } & 1.846791000 \\ \text { H } & 2.586717000 \\ \text { H } & 3.598307000 \\ \text { C } & 2.642757000 \\ \text { H } & 1.847850000 \\ \text { H } & 3.599311000 \\ \text { H } & 2.588185000 \\ \text { C } & 3.744819000 \\ \text { H } & 3.733376000 \\ \text { H } & 4.685747000 \\ \text { H } & 3.732702000\end{array}$

0.419033000

0.000073000

$-0.305284000$

0.032978000

$-1.661224000$

0.033558000

1.740693000

1.763417000

$-1.325590000$

$-0.261451000$

2.047593000

$-1.154137000$

$-1.904201000$

$-0.554519000$

$-1.688762000$

$-1.153194000$

$-1.903334000$

$-1.687689000$

$-0.552898000$

0.724423000

1.369375000

0.163871000

1.368733000

$-0.000226000$

$-1.102694000$

0.000174000

1.101490000

$-0.000139000$

$-0.000432000$

0.000616000

0.000153000

$-0.000111000$

$-1.266027000$

$-1.302918000$

$-2.180543000$

$-1.274092000$

1.266937000

1.304925000

1.274762000

2.181044000

$-0.000647000$

0.881948000

$-0.000804000$

$-0.883699000$

\section{1. $\mathrm{CF}_{3} \mathrm{COCHC}(\mathrm{OH})\left(\mathrm{CMe}_{3}\right)$}

$\begin{array}{lr}\text { C } & 1.180686000 \\ \text { C } & -0.048175000 \\ \text { C } & -1.257163000 \\ \text { C } & -2.609738000 \\ \text { F } & -3.620304000 \\ \text { F } & -2.500134000 \\ \text { F } & -2.965789000 \\ \text { O } & -1.324364000 \\ \text { O } & 1.244590000 \\ \text { H } & -0.097696000 \\ \text { C } & 2.543327000 \\ \mathrm{C} & 2.418625000 \\ \mathrm{H} & 1.899455000 \\ \mathrm{H} & 1.897584000 \\ \mathrm{H} & 3.420001000 \\ \mathrm{C} & 3.332900000 \\ \mathrm{H} & 2.817086000 \\ \mathrm{H} & 4.320681000 \\ \mathrm{H} & 3.470148000 \\ \mathrm{C} & 3.297390000 \\ \mathrm{H} & 3.429377000 \\ \mathrm{H} & 4.286679000 \\ \mathrm{H} & 2.756878000 \\ \mathrm{H} & 0.279297000\end{array}$

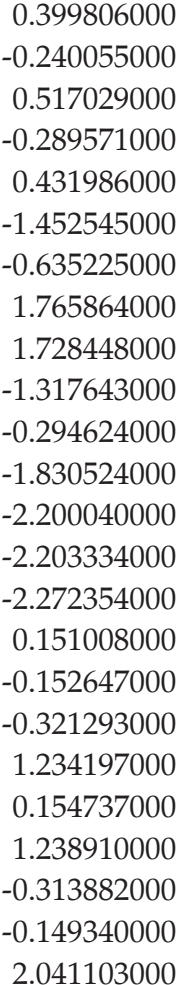

0.027611000

$-0.035836000$

$-0.036043000$

$-0.060630000$

$-0.596376000$

$-0.777547000$

1.217946000

0.014508000

0.088645000

$-0.087895000$

0.018156000

0.018723000

0.908658000

$-0.868474000$

0.016935000

1.277084000

2.194266000

1.273751000

1.304304000

$-1.262732000$

$-1.291006000$

$-1.287591000$

$-2.165381000$

0.075400000

\section{ThCOCHC(OH)(Th)}

$-0.527843000$

0.130891000

$-0.611146000$

$-1.862907000$

$-1.884752000$

1.211122000
$-0.000055000$

$-0.000008000$

0.000042000

$-0.000093000$

0.000074000

$-0.000013000$ 


$\begin{array}{lrrr}\mathrm{H} & 0.277946000 & -2.141071000 & -0.000070000 \\ \mathrm{C} & -2.763671000 & 1.492042000 & -0.000027000 \\ \mathrm{C} & -2.512420000 & 0.126742000 & 0.000036000 \\ \mathrm{~S} & -4.010656000 & -0.762860000 & 0.000101000 \\ \mathrm{C} & -4.933731000 & 0.683926000 & 0.000042000 \\ \mathrm{C} & -4.140688000 & 1.810085000 & -0.000022000 \\ \mathrm{H} & -1.986719000 & 2.249524000 & -0.000081000 \\ \mathrm{H} & -6.017258000 & 0.634577000 & 0.000065000 \\ \mathrm{H} & -4.533810000 & 2.823659000 & -0.000066000 \\ \mathrm{C} & 2.776379000 & 1.519560000 & -0.000029000 \\ \mathrm{C} & 2.500018000 & 0.159674000 & -0.000082000 \\ \mathrm{~S} & 3.981243000 & -0.760041000 & -0.000197000 \\ \mathrm{C} & 4.931509000 & 0.667627000 & -0.000189000 \\ \mathrm{C} & 4.158768000 & 1.807893000 & -0.000086000 \\ \mathrm{H} & 2.010828000 & 2.288671000 & 0.000051000 \\ \mathrm{H} & 6.013020000 & 0.592454000 & -0.000262000 \\ \mathrm{H} & 4.571660000 & 2.812990000 & -0.000059000\end{array}$

\section{3. $\mathrm{ThC}(\mathrm{OH}) \mathrm{CHCO}(\mathrm{Ph})$}

$\begin{array}{lrr}\mathrm{S} & -3.984530000 & -0.663409000 \\ \mathrm{O} & -1.346412000 & -1.907186000 \\ \mathrm{O} & 1.147231000 & -2.071815000 \\ \mathrm{H} & -0.356153000 & -2.232504000 \\ \mathrm{C} & -4.836791000 & 0.814893000 \\ \mathrm{H} & -5.917935000 & 0.806242000 \\ \mathrm{C} & -3.993757000 & 1.904079000 \\ \mathrm{H} & -4.338751000 & 2.928995000 \\ \mathrm{C} & -2.637300000 & 1.534982000 \\ \mathrm{H} & -1.825245000 & 2.254628000 \\ \mathrm{C} & -2.451367000 & 0.164509000 \\ \mathrm{C} & -1.213095000 & -0.591362000 \\ \mathrm{C} & 0.045826000 & -0.005712000 \\ \mathrm{H} & 0.127274000 & 1.055898000 \\ \mathrm{C} & 1.224821000 & -0.809739000 \\ \mathrm{C} & 2.572826000 & -0.154712000 \\ \mathrm{C} & 2.776327000 & 1.201890000 \\ \mathrm{H} & 1.957102000 & 1.811384000 \\ \mathrm{C} & 4.036193000 & 1.784719000 \\ \mathrm{H} & 4.175214000 & 2.834569000 \\ \mathrm{C} & 5.115991000 & 1.025032000 \\ \mathrm{H} & 6.096885000 & 1.483593000 \\ \mathrm{C} & 4.929599000 & -0.326515000 \\ \mathrm{H} & 5.768130000 & -0.923871000 \\ \mathrm{C} & 3.673633000 & -0.913608000 \\ \mathrm{H} & 3.525818000 & -1.964148000\end{array}$

\section{ThCOCHC(OH)(Ph)}

$\begin{array}{lrr}\mathrm{S} & -4.012086000 & -0.663092000 \\ \mathrm{O} & -1.326725000 & -1.937567000 \\ \mathrm{O} & 1.194530000 & -2.062498000 \\ \mathrm{H} & 0.188807000 & -2.284810000 \\ \mathrm{C} & -4.836480000 & 0.835453000 \\ \mathrm{H} & -5.917816000 & 0.852972000 \\ \mathrm{C} & -3.974721000 & 1.909672000 \\ \mathrm{H} & -4.300073000 & 2.943204000 \\ \mathrm{C} & -2.625005000 & 1.509911000\end{array}$

0.041149000

$-0.311546000$

$-0.358716000$

$-0.365308000$

0.220940000

0.301005000

0.243473000

0.348627000

0.112344000

0.102788000

$-0.006483000$

$-0.146492000$

$-0.101683000$

0.078904000

$-0.211750000$

$-0.111096000$

$-0.424398000$

$-0.796017000$

$-0.291952000$

$-0.545140000$

0.163518000

0.278205000

0.466429000

0.819681000

0.320875000

0.553846000

0.063728000

$-0.270470000$

$-0.333293000$

$-0.334116000$

0.219371000

0.302142000

0.222124000

0.310176000

0.097152000

$\begin{array}{lr}\text { H } & -1.801679000 \\ \text { C } & -2.464257000 \\ \text { C } & -1.237956000 \\ \text { C } & 0.038708000 \\ \text { H } & 0.091253000 \\ \text { C } & 1.214798000 \\ \text { C } & 2.559258000 \\ \text { C } & 2.779981000 \\ \text { H } & 1.965537000 \\ \text { C } & 4.048004000 \\ \text { H } & 4.202557000 \\ \text { C } & 5.119740000 \\ H & 6.108974000 \\ \text { C } & 4.915183000 \\ \text { H } & 5.745278000 \\ \text { C } & 3.649638000 \\ \text { H } & 3.490999000\end{array}$

2.216397000

0.134382000

$-0.676249000$

$-0.014534000$

1.050778000

$-0.735389000$

$-0.120727000$

1.232894000

1.847836000

1.794279000

2.841136000

1.016447000

1.458083000

$-0.331587000$

$-0.944934000$

$-0.898761000$

$-1.945834000$
0.075379000

0.000387000

$-0.134188000$

$-0.088770000$

0.081731000

$-0.187054000$

$-0.094938000$

$-0.410858000$

$-0.783841000$

$-0.281224000$

$-0.536563000$

0.165448000

0.271372000

0.467913000

0.813091000

0.332587000

0.571718000

\section{5. $\mathrm{PhCOCHC}(\mathrm{OH})(\mathrm{Ph})$}

$\begin{array}{lr}\mathrm{C} & -1.217484000 \\ \mathrm{C} & 0.003878000 \\ \mathrm{C} & 1.236345000 \\ \mathrm{O} & -1.277519000 \\ \mathrm{O} & 1.239744000 \\ \mathrm{H} & 0.020167000 \\ \mathrm{H} & -0.281775000 \\ \mathrm{C} & 2.537371000 \\ \mathrm{C} & 2.657860000 \\ \mathrm{C} & 3.674429000 \\ \mathrm{C} & 3.874660000 \\ \mathrm{C} & 4.886239000 \\ \mathrm{C} & 4.991103000 \\ \mathrm{H} & 1.807299000 \\ \mathrm{H} & 3.590181000 \\ \mathrm{H} & 3.951158000 \\ \mathrm{H} & 5.753770000 \\ \mathrm{H} & 5.937504000 \\ \mathrm{C} & -2.519288000 \\ \mathrm{C} & -2.663539000 \\ \mathrm{C} & -3.642818000 \\ \mathrm{C} & -3.890811000 \\ \mathrm{C} & -4.866690000 \\ \mathrm{C} & -4.995675000 \\ \mathrm{H} & -1.821828000 \\ \mathrm{H} & -3.542291000 \\ \mathrm{H} & -3.987247000 \\ \mathrm{H} & -5.723121000 \\ \mathrm{H} & -5.952606000\end{array}$

0.787922000

0.149822000

0.872817000

2.089555000

2.117631000

$-0.886281000$

2.365375000

0.144311000

$-1.240298000$

0.858700000

$-1.891664000$

0.203667000

$-1.173633000$

$-1.817494000$

1.929489000

$-2.962088000$

0.767526000

$-1.685045000$

0.107869000

$-1.277112000$

0.850721000

$-1.901155000$

0.221074000

$-1.156128000$

$-1.868588000$

1.920524000

$-2.971692000$

0.807752000

$-1.646543000$

\section{6. $\mathrm{CH}_{3} \mathrm{COCHC}(\mathrm{OH})\left(\mathrm{CH}_{3}\right)$}

$\begin{array}{lr}\text { C } & -1.206646000 \\ \text { C } & 0.010418000 \\ \text { C } & 1.244362000 \\ \text { O } & -1.285517000 \\ \text { O } & 1.254139000 \\ \text { H } & 0.033262000\end{array}$

$-0.073632000$

$-0.720432000$

0.023353000

1.257510000

1.285770000

$-1.805777000$
$-0.283683000$

$-0.145851000$

$-0.293915000$

$-0.567156000$

$-0.544509000$

0.159635000

$-0.610164000$

$-0.105705000$

$-0.324171000$

0.307791000

$-0.124547000$

0.523111000

0.309435000

$-0.676218000$

0.470226000

$-0.308526000$

0.861024000

0.478088000

$-0.095029000$

$-0.298783000$

0.308428000

$-0.088069000$

0.527228000

0.332457000

$-0.648130000$

0.464348000

$-0.259408000$

0.853633000

0.501693000

0.000028000

0.000101000

0.000136000

0.000011000

0.000040000

0.000093000 


$\begin{array}{lrrr}\mathrm{H} & -0.302090000 & 1.553361000 & 0.000071000 \\ \mathrm{C} & 2.547552000 & -0.754712000 & -0.000061000 \\ \mathrm{H} & 2.599499000 & -1.408316000 & 0.880029000 \\ \mathrm{H} & 2.599786000 & -1.407233000 & -0.880946000 \\ \mathrm{H} & 3.401778000 & -0.075736000 & 0.000462000 \\ \mathrm{C} & -2.527492000 & -0.779379000 & -0.000065000 \\ \mathrm{H} & -3.107485000 & -0.484113000 & -0.882528000 \\ \mathrm{H} & -2.400934000 & -1.863895000 & 0.000064000 \\ \mathrm{H} & -3.107715000 & -0.483920000 & 0.882180000\end{array}$

\section{7. $\mathrm{PhCOCHC(OH})\left(\mathrm{CH}_{3}\right)$}

$\begin{array}{lr}\mathrm{C} & 0.471368000 \\ \mathrm{C} & 1.461597000 \\ \mathrm{C} & 2.808148000 \\ \mathrm{O} & 0.816335000 \\ \mathrm{O} & 3.239938000 \\ \mathrm{C} & 3.887057000 \\ \mathrm{H} & 3.469274000 \\ \mathrm{H} & 4.532342000 \\ \mathrm{H} & 4.519236000 \\ \mathrm{C} & -0.988616000 \\ \mathrm{C} & -1.922545000 \\ \mathrm{C} & -1.460747000 \\ \mathrm{C} & -3.281273000 \\ \mathrm{C} & -2.822285000 \\ \mathrm{C} & -3.736962000 \\ \mathrm{H} & -1.566136000 \\ \mathrm{H} & -0.772698000 \\ \mathrm{H} & -3.990162000 \\ \mathrm{H} & -3.169535000 \\ \mathrm{H} & -4.798835000 \\ \mathrm{H} & 2.363709000 \\ \mathrm{H} & 1.169347000\end{array}$

0.482083000

$-0.538247000$

$-0.239679000$

1.679212000

0.991364000

$-1.250196000$

$-2.234308000$

$-1.326301000$

$-0.929736000$

0.131957000

1.144456000

$-1.178478000$

0.850871000

$-1.468216000$

$-0.456045000$

2.160033000

$-1.981302000$

1.643985000

$-2.486379000$

$-0.684416000$

1.524559000

$-1.550105000$

\section{8. $\mathrm{PhC}(\mathrm{OH}) \mathrm{CHCO}\left(\mathrm{CH}_{3}\right)$}

$\begin{array}{lr}C & 0.735759000 \\ C & 1.853404000 \\ C & 3.167403000 \\ \text { O } & 0.894946000 \\ \text { O } & 3.349931000 \\ C & 4.372532000 \\ H & 4.096963000 \\ H & 4.932462000 \\ H & 5.043514000 \\ C & -0.668232000 \\ C & -1.700233000 \\ C & -1.015203000 \\ C & -3.031049000 \\ C & -2.347046000 \\ C & -3.361506000 \\ H & -1.446704000 \\ H & -0.251051000 \\ H & -3.813041000 \\ H & -2.595932000 \\ H & -4.401716000\end{array}$

0.113121000

$-0.611468000$

$-0.078206000$

1.302557000

1.054867000

$-0.877764000$

$-1.843299000$

$-0.299970000$

$-1.043223000$

$-0.337939000$

0.422974000

$-1.502486000$

0.030850000

$-1.890594000$

$-1.126829000$

1.323229000

$-2.110769000$

0.633112000

$-2.791852000$

$-1.431840000$

0.052824000

0.006682000

$-0.409621000$

$-0.257389000$

0.248878000

0.471645000

$-0.634523000$

1.085427000

$-0.095379000$

0.183654000

$-0.293932000$

0.284798000

$-0.207604000$

0.090532000

0.329894000

$-0.543736000$

0.516267000

$-0.375507000$

0.168454000

$-0.375003000$

0.302224000

0.298658000

$-0.098429000$

0.099195000

0.870650000

0.643324000

$-0.353319000$

$-0.786269000$

$-1.098012000$

0.497086000

0.142821000

0.722334000

$-0.569246000$

0.598602000

$-0.692499000$

$-0.108525000$

1.272199000

$-1.043690000$

1.057073000

$-1.249785000$

$-0.207244000$

$\begin{array}{lrrr}\mathrm{H} & 1.936198000 & 1.422967000 & 0.887900000 \\ \mathrm{H} & 1.743696000 & -1.587630000 & -0.551655000\end{array}$

\section{9. $\left(\mathrm{CCH}_{3}\right) \mathrm{C}(\mathrm{OH}) \mathrm{CHCO}\left(\mathrm{CCH}_{3}\right)$}

$-0.403550000$

$-0.000289000$

C $\quad-0.005677000$

0.255110000

$-0.000307000$

C $\quad 1.232679000$

$-0.473338000$

$-1.733573000$

$-0.000374000$

$-0.000453000$

$-1.740389000$

1.332590000

$-2.001750000$

$-0.000223000$

$-0.000211000$

$-0.000760000$

0.000047000
$-0.000096000$

0.267215000

0.279573000

1.804739000

2.177369000

2.178564000

2.253644000

$-0.169704000$

0.297250000

0.140600000

$-1.254343000$

$-0.171276000$

$-1.255969000$

0.138134000

0.295471000

$-0.171389000$

0.139201000

0.287349000

1.817182000

2.192619000

2.252130000

2.192606000

$-0.171314000$

$-1.256687000$

0.287250000

0.139528000

$-0.001133000$

$-0.889902000$

0.886839000

$-0.001133000$

1.267328000

1.277701000

2.178150000

1.298836000

$-1.265956000$

$-1.296116000$

$-2.177829000$

$-1.275518000$

1.269823000

2.177961000

1.284143000

1.300281000

0.000055000

$-0.888156000$

0.000230000

0.888095000

$-1.269345000$

$-1.299916000$

$-1.282998000$

$-2.177746000$

\section{0. $\left(\mathrm{OCH}_{3}\right) \mathrm{COCHC}(\mathrm{OH})\left(\mathrm{CH}_{3}\right)$}

$\begin{array}{lr}\mathrm{C} & 1.678486000 \\ \mathrm{C} & 0.467052000 \\ \mathrm{C} & -0.772626000 \\ \mathrm{O} & 1.799136000 \\ \mathrm{O} & -0.857010000 \\ \mathrm{H} & 0.424559000 \\ \mathrm{H} & 0.858527000 \\ \mathrm{O} & -1.865201000 \\ \mathrm{C} & -3.157195000 \\ \mathrm{H} & -3.285225000 \\ \mathrm{H} & -3.273771000 \\ \mathrm{H} & -3.885459000 \\ \mathrm{C} & 2.988514000 \\ \mathrm{H} & 3.597202000 \\ \mathrm{H} & 3.548973000 \\ \mathrm{H} & 2.843616000\end{array}$

$-1.256748000$
0.094631000

0.024389000

0.095791000

0.231110000

0.225466000

$-0.087588000$

0.264444000

0.003802000

0.069975000

1.027246000

$-0.747320000$

$-0.026761000$

0.031822000

$-0.787800000$

0.960807000

$-0.116770000$ 


\section{1. $\left(\mathrm{OCH}_{3}\right) \mathrm{C}(\mathrm{OH}) \mathrm{CHCO}\left(\mathrm{CH}_{3}\right)$}

optimiseer tot $\left(\mathrm{OCH}_{3}\right) \mathrm{COCHC}(\mathrm{OH})\left(\mathrm{CH}_{3}\right)$

\section{2. $\mathrm{CF}_{3} \mathrm{C}(\mathrm{OH}) \mathrm{CHCO}(\mathrm{ThTh})$}

$\begin{array}{lr}\text { C } & -3.808534000 \\ \text { C } & -2.535604000 \\ \text { C } & -1.402919000 \\ \text { O } & -4.110276000 \\ \text { O } & -1.591945000 \\ \text { H } & -2.390539000 \\ \text { C } & 4.651655000 \\ \text { C } & 3.889315000 \\ \text { S } & 4.943612000 \\ \text { C } & 6.355874000 \\ \text { C } & 6.047011000 \\ \text { H } & 4.216249000 \\ \text { H } & 7.333318000 \\ \text { H } & 6.798948000 \\ \text { C } & 0.351831000 \\ \text { C } & -0.048138000 \\ \text { S } & 1.350574000 \\ \text { C } & 2.450558000 \\ \text { C } & 1.741662000 \\ \text { H } & -0.338919000 \\ \text { H } & 2.223792000 \\ \text { C } & -5.047486000 \\ \text { F } & -5.820569000 \\ \text { F } & -5.816477000 \\ \text { F } & -4.713939000 \\ \text { H } & -3.183850000 \\ & \end{array}$

0.017179000

$-0.020843000$

0.000664000

0.070086000

0.051656000

$-0.061287000$

$-0.215843000$

$-0.098059000$

0.045404000

$-0.060475000$

$-0.194577000$

$-0.327069000$

$-0.015940000$

$-0.278968000$

$-0.122180000$

$-0.036506000$

0.019778000

$-0.086316000$

$-0.150190000$

$-0.171800000$

$-0.228454000$

$-0.000237000$

1.103588000

$-1.100290000$

$-0.022775000$

0.073521000

\section{3. $\mathrm{CF}_{3} \mathrm{COCHC}(\mathrm{OH})(\mathrm{ThTh})$}

$\begin{array}{lr}\text { C } & -3.809973000 \\ \text { C } & -2.539399000 \\ \text { C } & -1.383417000 \\ \text { O } & -4.001255000 \\ \text { O } & -1.474558000 \\ \text { H } & -2.463907000 \\ \text { H } & -2.483453000 \\ \text { C } & 4.584307000 \\ \text { C } & 3.886418000 \\ \text { S } & 5.007253000 \\ \text { C } & 6.366115000 \\ \text { C } & 5.988610000 \\ \text { H } & 4.094414000 \\ \text { H } & 7.366849000 \\ \text { H } & 6.697186000 \\ \text { C } & 0.378565000 \\ \text { C } & -0.040159000 \\ \text { S } & 1.338768000\end{array}$

$\begin{array}{lr}\text { C } & 2.457612000 \\ \text { C } & 1.771620000 \\ \text { H } & -0.303720000 \\ \text { H } & 2.272874000 \\ \text { C } & -5.092651000 \\ \text { F } & -5.849758000 \\ \text { F } & -5.858217000 \\ \text { F } & -4.805065000\end{array}$

$-0.220143000$

$-1.428314000$

$-2.123236000$

$-2.384270000$

$-0.497494000$

$-0.289712000$

$-0.206020000$

$-1.837156000$

\section{4. $\mathrm{CF}_{3} \mathrm{COCHC}(\mathrm{OH})(\mathrm{Fu})$}

-0.093141000
-0.202301000
-0.260474000
-0.318875000
0.002207000
1.116201000
-1.087727000
-0.050410000

$-0.000125000$ $-0.002556000$ $-0.005417000$ $-0.000453000$ 0.000588000 0.001873000 0.000079000 0.002833000 $-0.002302000$ $-0.001535000$ 0.000684000 0.000483000 $-1.103035000$ 0.002048000 1.102661000 $-0.001374000$ 0.002258000 $-0.003163000$ 0.006468000

\section{5. $\mathrm{CF}_{3} \mathrm{C}(\mathrm{OH}) \mathrm{CHCO}(\mathrm{Fu})$}

$\begin{array}{lr}\text { C } & 2.253292000 \\ \text { C } & 1.945070000 \\ \text { O } & 3.115893000 \\ \text { C } & 4.137014000 \\ \text { C } & 3.666581000 \\ \text { H } & 1.553605000 \\ \text { H } & 5.134745000 \\ \text { H } & 4.260067000 \\ \text { C } & 0.675486000 \\ \text { C } & -0.554435000 \\ \text { C } & -1.755635000 \\ \text { C } & -3.103233000 \\ \text { F } & -3.838113000 \\ \text { F } & -2.943200000 \\ \text { F } & -3.835910000 \\ \text { O } & -1.885925000 \\ \text { O } & 0.649319000 \\ \text { H } & -0.534783000 \\ \text { H } & -0.907576000\end{array}$

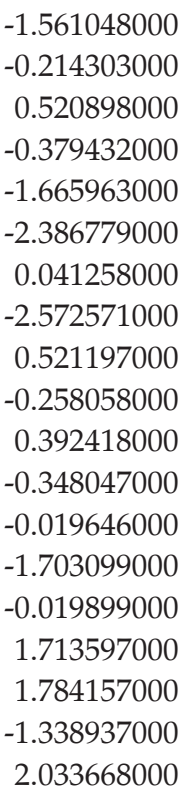

$-0.004641000$ 0.000027000 0.004250000 0.000676000 $-0.002618000$ $-0.008711000$ 0.002702000 $-0.004852000$ 0.000732000 0.000648000 0.001493000 0.002734000 $-1.098549000$ 0.002382000 1.105608000 0.001052000 $-0.001073000$ 0.000905000 $-0.001857000$ 


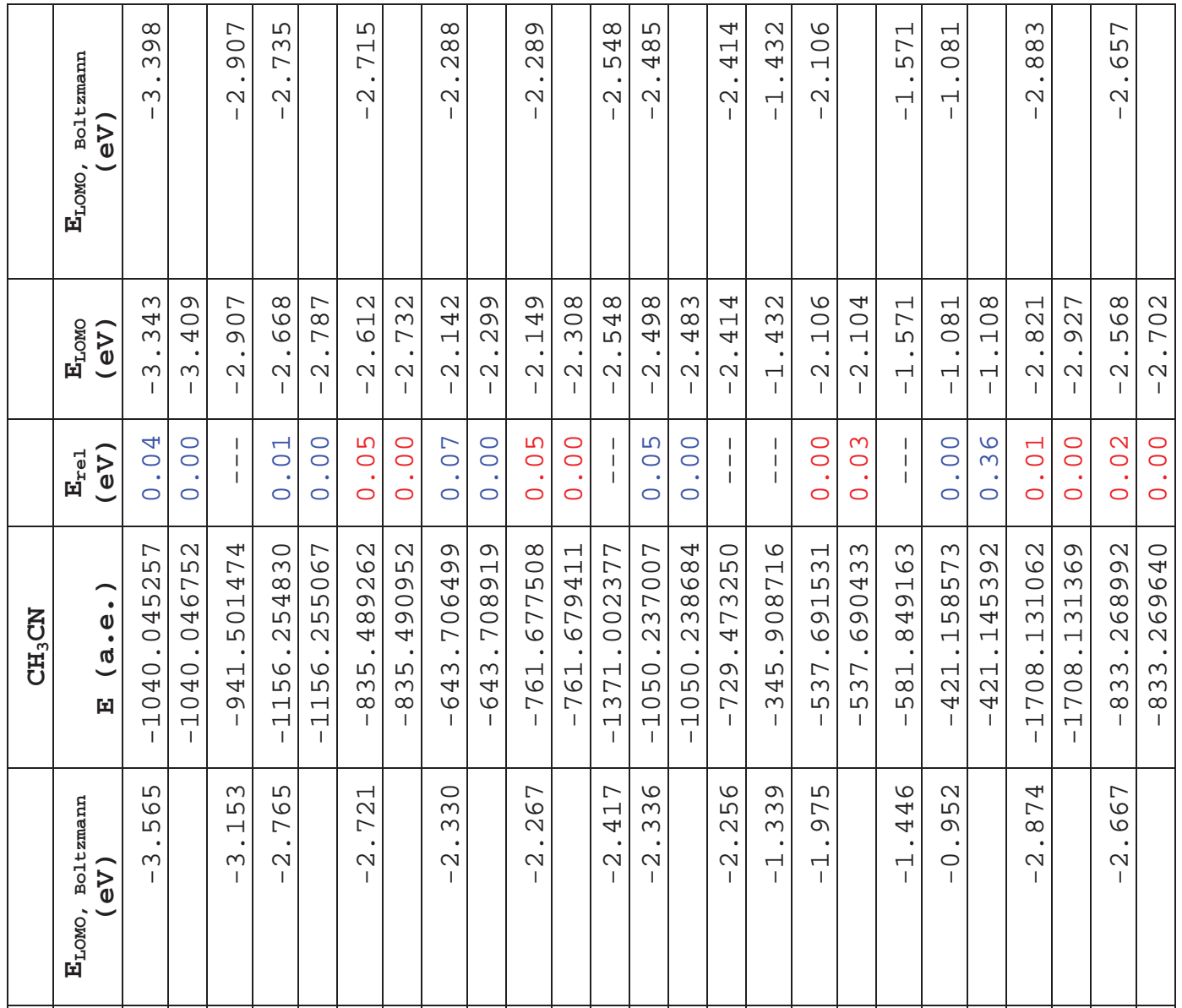

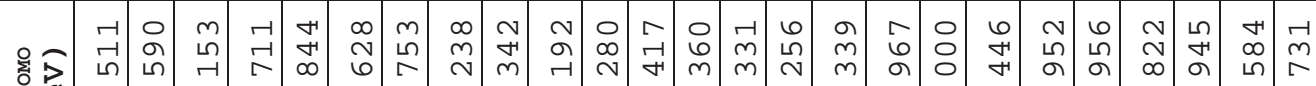
皇

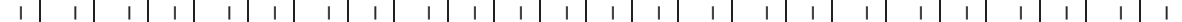

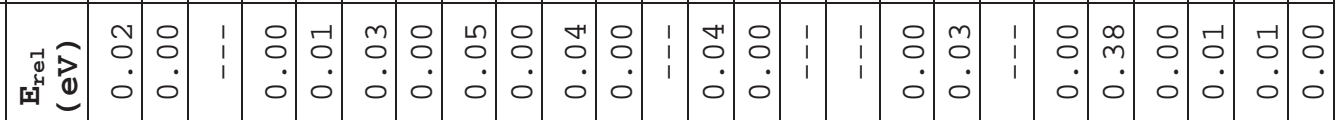

m)

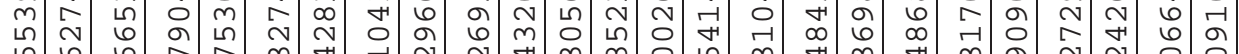

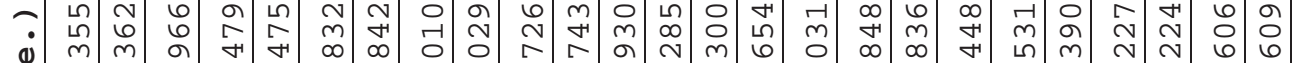

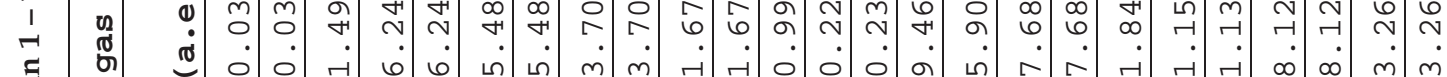

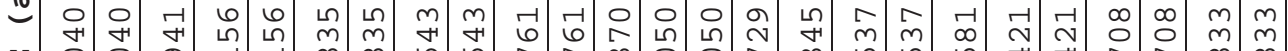

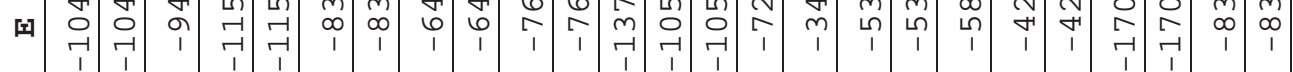

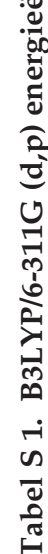

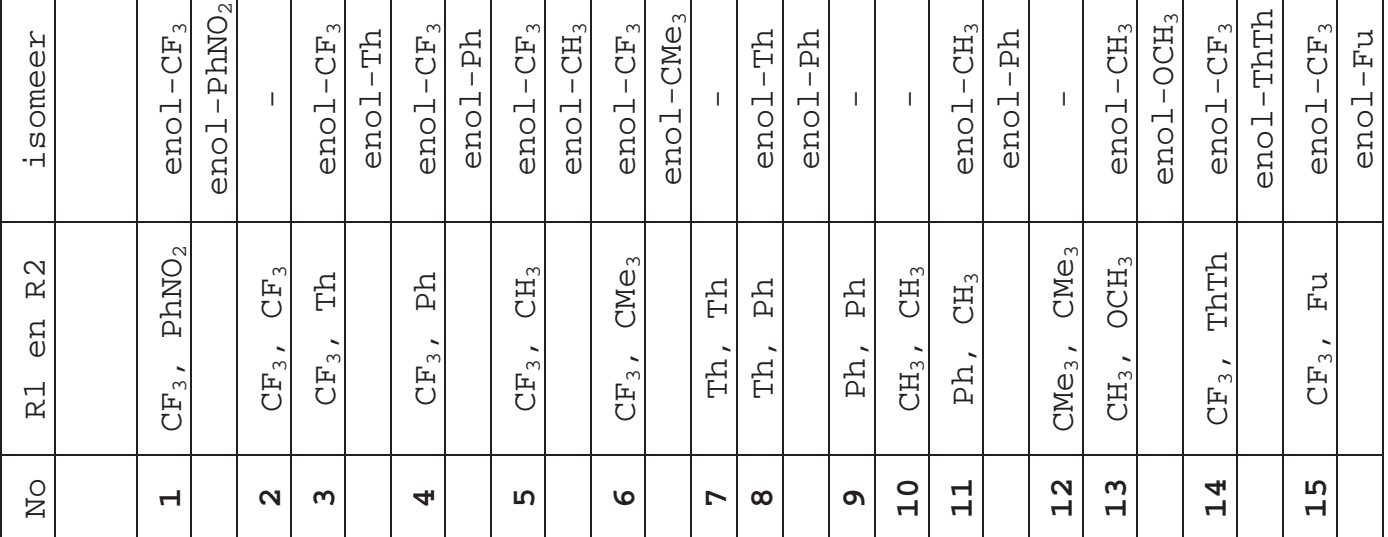




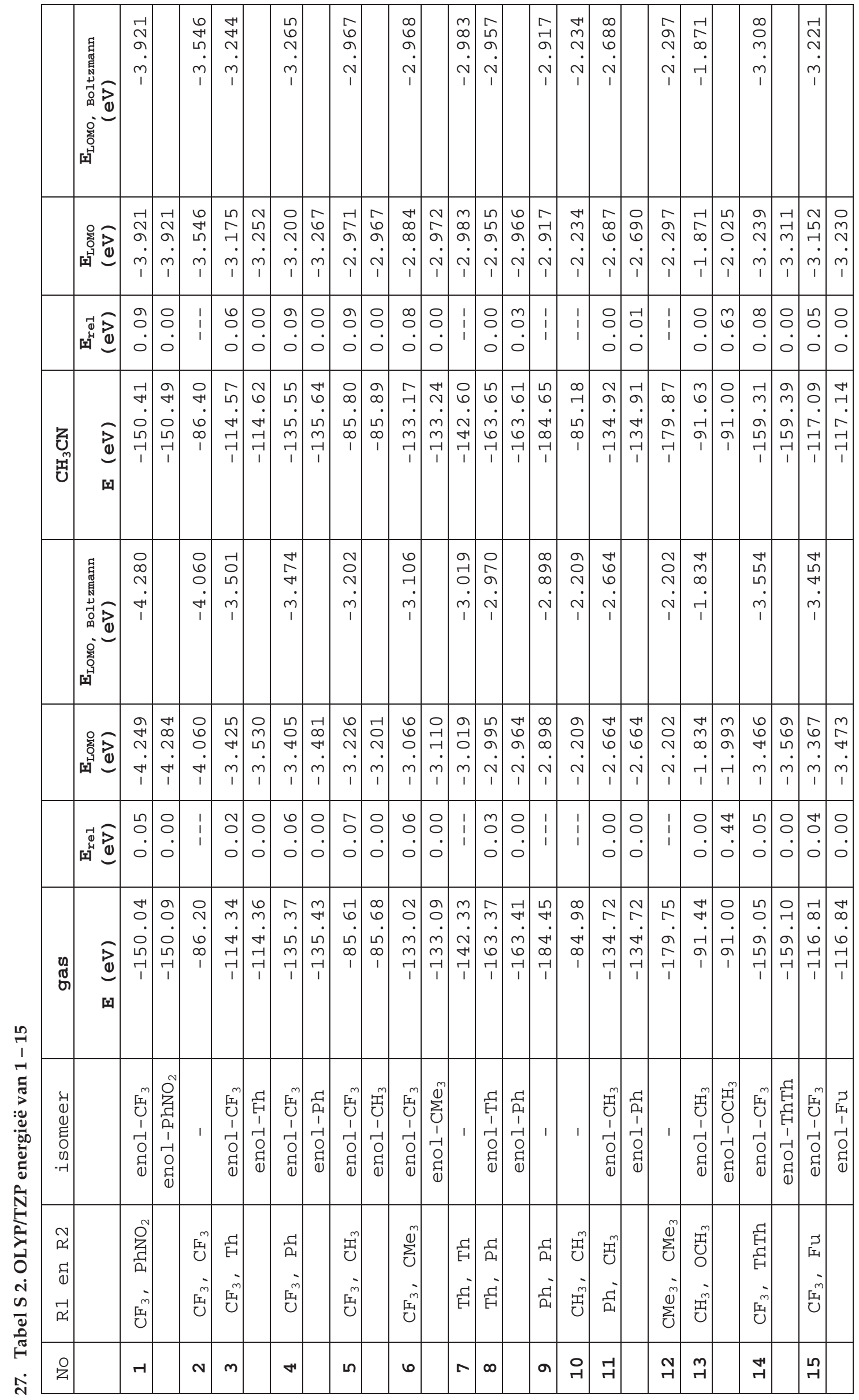


28. Tabel S 3. MESP potensiaal op O van B3LYP/6-311G(d,p) geoptimiseerde geometrieë van die gereduseerde $1-15$.

\begin{tabular}{|c|c|c|c|c|c|}
\hline & & & & MESP Potensiaal & \\
\hline No & R1 & R2 & isomeer & o-enol & $\mathrm{O}_{\mathrm{co}}$ \\
\hline \multirow[t]{2}{*}{1} & $\mathrm{CF}_{3}$ & $\mathrm{Ph}-\mathrm{NO}_{2}$ & enol-CF 3 & -22.468 & -22.52 \\
\hline & & & enol-PhNO 2 & -22.468 & -22.52 \\
\hline 2 & $\mathrm{CF}_{3}$ & $\mathrm{CF}_{3}$ & & -22.522 & -22.58 \\
\hline \multirow[t]{2}{*}{3} & $\mathrm{CF}_{3}$ & Th & enol- $\mathrm{CF}_{3}$ & -22.515 & -22.58 \\
\hline & & & enol-Th & -22.512 & -22.57 \\
\hline \multirow[t]{2}{*}{4} & $\mathrm{CF}_{3}$ & $\mathrm{Ph}$ & enol-CF 3 & -22.521 & -22.58 \\
\hline & & & enol-Ph & -22.518 & -22.57 \\
\hline \multirow[t]{2}{*}{5} & $\mathrm{CF}_{3}$ & $\mathrm{CH}_{3}$ & enol-CF 3 & -22.548 & -22.61 \\
\hline & & & enol- $\mathrm{CH}_{3}$ & -22.549 & -22.61 \\
\hline \multirow[t]{2}{*}{6} & $\mathrm{CF}_{3}$ & tBu & enol-CF 3 & -22.541 & -22.60 \\
\hline & & & enol-tBu & -22.542 & -22.60 \\
\hline 7 & Th & Th & & -22.515 & -22.57 \\
\hline \multirow[t]{2}{*}{8} & $\mathrm{Ph}$ & Th & enol-Th & -22.519 & -22.57 \\
\hline & & & enol-Ph & -22.520 & -22.57 \\
\hline 9 & $\mathrm{Ph}$ & $\mathrm{Ph}$ & & -22.524 & -22.58 \\
\hline 10 & $\mathrm{CH}_{3}$ & $\mathrm{CH}_{3}$ & & -22.577 & -22.64 \\
\hline \multirow[t]{2}{*}{11} & $\mathrm{CH}_{3}$ & $\mathrm{Ph}$ & enol- $\mathrm{CH}_{3}$ & -22.538 & -22.60 \\
\hline & & & enol-Ph & -22.537 & -22.59 \\
\hline 12 & $\mathrm{CMe}_{3}$ & $\mathrm{CMe}_{3}$ & & -22.561 & -22.62 \\
\hline \multirow[t]{2}{*}{13} & $\mathrm{OCH}_{3}$ & $\mathrm{CH}_{3}$ & enol- $\mathrm{CH}_{3}$ & -22.567 & -22.62 \\
\hline & & & enol- $\mathrm{OCH}_{3}$ & -22.566 & -22.63 \\
\hline \multirow[t]{2}{*}{14} & $\mathrm{CF}_{3}$ & ThTh & enol-CF 3 & -22.487 & -22.55 \\
\hline & & & enol-ThTh & -22.486 & -22.54 \\
\hline \multirow[t]{2}{*}{15} & $\mathrm{CF}_{3}$ & $\mathrm{Fu}$ & enol- $\mathrm{CF}_{3}$ & -22.529 & -22.59 \\
\hline & & & enol-Fu & -22.527 & -22.58 \\
\hline
\end{tabular}

